\title{
Is an Epic Pluvial Masking the Water Insecurity of the Greater New York City Region?*,+
}

\author{
Neil Pederson,, Andrew R. Bell,,${ }^{\#}$ Edward R. CoOK,,${ }^{\#}$ Upmanu Lall, ${ }^{@}$ NAResh Devineni, ${ }^{\&}$ \\ Richard SEAGER, ${ }^{* *}$ KeIth EgGleston, ${ }^{++}$AND KeVIn P. VRANES ${ }^{\# \#}$ \\ \# Tree Ring Laboratory, Lamont-Doherty Earth Observatory, Columbia University, Palisades, New York \\ ${ }^{\circledR}$ Department of Earth and Environmental Engineering, Columbia Water Center, Columbia University, New York, New York \\ \& Columbia Water Center, The Earth Institute, Columbia University, New York, New York \\ ** Lamont-Doherty Earth Observatory, Columbia University, Palisades, New York \\ ${ }^{++}$Northeast Regional, Climate Center, Ithaca, New York \\ \#\# Boulder, Colorado
}

(Manuscript received 9 December 2011, in final form 25 May 2012)

\begin{abstract}
Six water emergencies have occurred since 1981 for the New York City (NYC) region despite the following: 1) its perhumid climate, 2) substantial conservation of water since 1979, and 3) meteorological data showing little severe or extreme drought since 1970. This study reconstructs 472 years of moisture availability for the NYC watershed to place these emergencies in long-term hydroclimatic context. Using nested reconstruction techniques, 32 tree-ring chronologies comprised of 12 species account for up to $66.2 \%$ of the average MayAugust Palmer drought severity index. Verification statistics indicate good statistical skill from 1531 to 2003. The use of multiple tree species, including rarely used species that can sometimes occur on mesic sites like Liriodendron tulipifera, Betula lenta, and Carya spp., seems to aid reconstruction skill. Importantly, the reconstruction captures pluvial events in the instrumental record nearly as well as drought events and is significantly correlated to precipitation over much of the northeastern United States. While the mid-1960s drought is a severe drought in the context of the new reconstruction, the region experienced repeated droughts of similar intensity, but greater duration during the sixteenth and seventeenth centuries. The full record reveals a trend toward more pluvial conditions since ca. 1800 that is accentuated by an unprecedented 43-yr pluvial event that continues through 2011. In the context of the current pluvial, decreasing water usage, but increasing extra-urban pressures, it appears that the water supply system for the greater NYC region could be severely stressed if the current water boom shifts toward hydroclimatic regimes like the sixteenth and seventeenth centuries.
\end{abstract}

\section{Introduction}

Despite a perhumid climate, a lack of extreme drought (Fig. 1; supplemental Fig. S1), increased precipitation since the 1960s (Horton et al. 2011; Seager et al. 2012) and

\footnotetext{
* Supplemental information related to this paper is available at the Journals Online website: http://dx.doi.org/10.1175/JCLI-D-1100723.s1.

${ }^{+}$Lamont-Doherty Earth Observatory Contribution Number 7579.

Corresponding author address: Neil Pederson, Tree Ring Laboratory of Lamont-Doherty Earth Observatory and Columbia University, P.O. Box 1000, 61 Rt. 9W, Palisades, NY 10964.

E-mail: adk@ldeo.columbia.edu
}

significant reduction in water consumption (from a peak of 787 liters per person per day in 1988 to 477 in 2009), the New York City (NYC) metropolitan region has suffered a series of water warnings and emergencies (1980-82, $1985,1989,1991,1995$, and 2002) in the last three decades (NYC Department of Environmental Protection 2011). This resource stress under favorable conditions highlights the challenge of maintaining reliable water supply to an urban metropolis of more than 8 million people. The population of the five boroughs of NYC is expected to swell to more than 9 million by 2030 (NYC Department of City Planning 2006), suggesting that, without concomitant increases in water supply, such emergency states may become a more frequent occurrence. Recent scholarship has pointed to an upward trend in precipitation and a downward trend in consecutive dry days in 


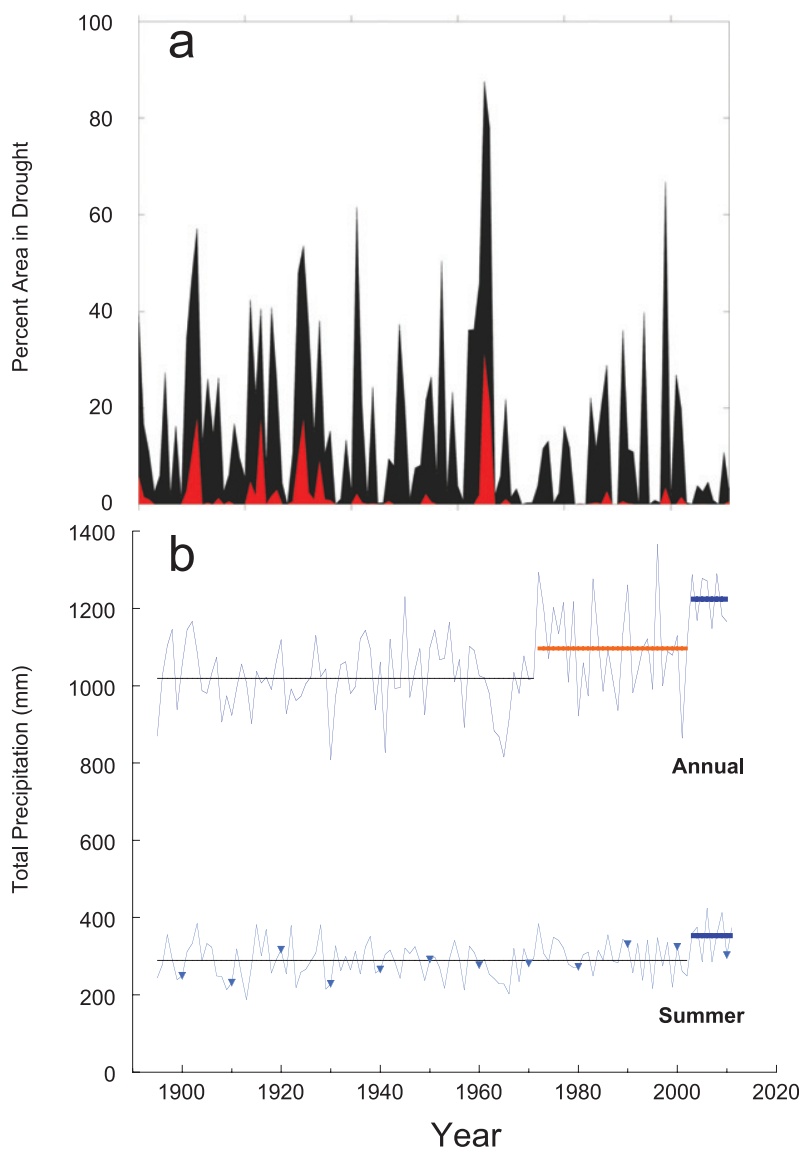

FIG. 1. (a) May-August annual drought area index for the northeastern United States from 1900 to 2011 (NOAA Northeast Regional Climate Center, Cornell University). As determined by the U.S. Drought Monitor (http://droughtmonitor.unl.edu/), black represents moderate and severe drought (PDSI from -2.0 to -3.9 ) while red represents extreme drought (PDSI $<-4.0$ ). (b) Instrumental records of precipitation from 1895 to 2011 for the northeastern United States. The top series (solid, blue line) is the average total annual precipitation while the bottom series (solid, light-blue line with triangles) is average total summer precipitation. Horizontal lines represent average precipitation for the regimes detected using the methods of Rodionov (2004). Data are derived from NOAA's National Climatic Data Center/Climate Services and Monitoring Division (http://www. ncdc.noaa.gov/temp-and-precip/time-series/).

meteorological records of the Northeast United States since the region's last extreme drought in 1962-66 (e.g., Burns et al. 2007; Spierre and Wake 2010). However, it would be risky to infer that NYC's future water supply is secure on the basis of this poorly understood trend. A longer, regional context, and understanding of the potential forcing factors driving this trend, is necessary to fully consider the water security of NYC and its surrounding region.

A recent analysis of precipitation variability across NYC's Catskill Mountains water supply region was performed by Seager et al. (2012). A survey of 23 meteorological stations covering the Catskill Mountains and the lower Hudson Valley, immediately north of NYC, indicates 1) that the 1960 s drought is the most significant in the century long instrumental record, and 2) that there has been a detectable increase in precipitation throughout the region since the early 1970s. This increase, when averaged across the region, resembles a step-change increase in precipitation, a shift also seen in an analysis focused solely on NYC (Horton et al. 2011). Neither the 1960s drought nor the recent pluvial seem forced by sea surface temperatures variations or related to radiatively driven climate change (Seager et al. 2012). Instead the 1960s drought coincided with an extreme negative phase of the North Atlantic Oscillation (NAO) (Namias 1966; Horton et al. 2009; Seager et al. 2012) while the shift to wetter conditions in the 1970s was also associated with a shift to a more positive phase of the NAO (Seager et al. 2012). However, no apparent links between Catskills precipitation and the NAO were found at shorter time scales. Seager et al. (2012) concluded that the main driver of precipitation variability in the region over the last 110 years was therefore probably internal atmospheric variability. This conclusion needs to be evaluated in the context of much longer records to aid in identifying the frequency and severity of droughts and pluvial events as well as trends of regional hydroclimate and to better understand the mechanisms of climate variability in the region.

Tree-ring analysis is used here to expand our long-term knowledge of drought variation in the NYC watershed and surrounding region. Beginning with the classic demonstration by Stockton and Jacoby (1976) that water resource management plans were based on insufficient records of climate variability, tree-ring based reconstructions of hydroclimate have recently assisted in understanding long-term climate patterns and trends for water resource management and their influence on society (e.g., Cook and Jacoby 1977, 1983; Stahle et al. 1988; Woodhouse and Lukas 2006; Buckley et al. 2010; Gou et al. 2010; Woodhouse et al. 2010; Büntgen et al. 2011; Maxwell et al. 2011; Meko and Woodhouse 2011; Pederson et al. 2012a). A study of water shortages and drought from 1900 to 2002 in Rockland County, New York, just north of NYC, found a significant disagreement between water supply and usage in recent decades (Lyon et al. 2005). When Lyon et al. (2005) explored longer, regional drought history using the North American Drought Atlas (NADA) (Cook and Krusic 2004; Cook et al. 1999, 2008), they concluded that the recent drought was within the range of natural variability and there were eight others comparable to the 1960s drought. A new reconstruction in the Delaware River basin indicates the 1960s drought to be the most severe over the 
last approximately 260 years (Devineni et al. 2013). However, the most recent reconstruction of drought variability specifically for the Hudson Valley, New York (Cook and Jacoby 1977), was completed during the beginning of the recent wetting trend (Fig. 1; supplemental Fig. S1). An update lengthening the record of drought history for the Hudson Valley and NYC watershed is necessary to better place the recent unusual pluvial conditions in a long-term context.

Here we use nested reconstruction techniques on a network with increased chronology and species replication to lengthen the original NYC watershed drought record by 240 years. The new reconstruction is used to place the recent increase in pluvial conditions in context. Analysis of instrumental records indicates a significant shift in rainfall since 2003 (Fig. 1; supplemental Fig. S1). We demonstrate that the recent wetting trend and pluvial, that is, multiple years marked by unusual rainfall and moist conditions, is an anomaly in NYC's approximately 500 -yr climate history. Placing the current pluvial in a broad context, along with the severe unexplained 1960s drought that preceded it, it is evident that the region will need to be adaptive and flexible to adequately ensure a reliable water supply to the 9.1 million residents of NYC's future.

\section{Methods}

\section{a. Development of the tree ring network}

The network of 33 tree-ring records used here is derived from a dendroecological study from 1999 to 2004 (Pederson 2005; number of chronologies $=23$ ) and inhouse chronologies (supplemental material, Table S1; number of chronologies $=10$ ); seven in-house chronologies are available from the International TreeRing Databank (ITRDB, http://www.ncdc.noaa.gov/ paleo/treering.html). Chronologies within or adjacent to the Hudson Valley were selected for a potential relationship to growing season Palmer drought severity index (PDSI) and at least 160 years in length were retained as potential climate predictors; segment length has a median of 163 years and ranges from 105 to 252 years (supplemental material, Table S1). Overall, the current tree-ring network in the NYC watershed, composed of 33 chronologies and contains three chronologies dating back to 1453 (supplemental Table S1, Fig. S2), is denser in time and space than all prior reconstructions.

Perhaps the most significant advance of the new network is its species composition. Here we take advantage of the biodiversity of forests in New York State's Hudson Valley to increase spatial and species replication. Recent work suggests that increased species replication could improve climatic reconstructions (García-Suárez et al. 2009; Cook and Pederson 2011), a hypothesis that has found support in a reconstruction of Potomac River flow using nine tree species from the diverse forests of the Appalachian Mountains (Maxwell et al. 2011). Twelve species are used here, including what we believe are four species not previously used for drought reconstruction (Betula lenta, Carya glabra, Quercus rubra, and Quercus velutina), and two species only recently used for drought reconstruction (Carya ovata and Liriodendron tulipifera) (supplemental material, Table S1). We will use the term "novel" when discussing these species not traditionally used in dendroclimatic research. The regional forest is so species rich that there are three species present at 1453 in the new network.

Standard tree-ring methods were used in the processing and crossdating of all new samples (Fritts 1976; Cook and Kariukstis 1990). The program ARSTAN was used to standardize all raw ring-width series (Cook et al. 2011) with the goal to retain as much long-term variation in ring widths as possible from trees living in close-canopy forests, where tree-to-tree competition can obscure the potential climate signal (Cook and Peters 1981; Pederson et al. 2004). We applied the "Friedman Super Smoother" to reduce the influence of changes in tree competition on annual radial increment (Friedman 1984; Buckley et al. 2010). Occasionally, the Friedman Super Smoother curve trends in opposition to raw ring-width trends at the end of a time series, resulting in ring index inflation or deflation. Series with these end-fitting issues were detrended using a two-thirds cubic smoothing spline (Cook and Peters 1981). Prior to detrending, series were transformed using the adaptive power transformation and stabilized using the "rbar" weighted stabilization method, where three or more trees are present for nearly all of the chronology length. A combination of the rbar weighted and one-third spline methodology was applied to records with greater replication at the beginning of the chronology (Cook and Peters 1997). A robust biweight mean function was used to calculate series index values (Cook 1985).

Chronology quality was interpreted using expressed population signal (EPS) (Wigley et al. 1984). Median network EPS is 0.950 and ranges from 0.860 to 0.981 . To maximize usable chronology length, the cutoff for each record was the first year in which EPS was $\geq 0.85$. The median year of earliest usable chronology within the network is 1780 , with a range from 1515 to 1852 (supplemental material, Table S1). Only ARSTAN chronologies were used as potential climate predictors. Autoregressive modeling reduces much of the stochastic or endogenous disturbances reflected in the tree rings of surviving trees such that the ARSTAN chronology is useful for the examination of long-term climate variability (Cook 1985). All tree-ring collections showed considerable 
instances of abrupt changes in ring width that are indicative of changes in tree-to-tree competition.

\section{b. Reconstruction of hydroclimate}

The target dataset for reconstruction was the instrumental PDSI for National Oceanic and Atmospheric Administration (NOAA)'s New York State's Climate Division 5 (from the National Climatic Data Center's Climate Data Online portal at http://www7.ncdc.noaa. gov/CDO/cdo), which represents the Hudson Valley. Average May-August PDSI within the Hudson Valley division was reconstructed based upon the common response of the tree-ring network. Ring index of the current year $(t)$ and prior year $(t+1)$ was used for each chronology because current-year ring widths and growth are often composed of energy gained during the prior year (Trumbore et al. 2002; Kagawa et al. 2006). Considering this physiological lag, 66 candidate predictors entered the regression matrix (33 current-year predictors and 33 lagged predictors). Predictor selection was based upon a one-tailed correlation (because of the requirement of a positive relation between ring widths and PDSI) at $p=0.05$. The Spruce Glen Tsuga canadensis record did not pass the selection criteria so that 32 of the 33 original chronologies were used as predictors. The final set of predictors was reduced to orthogonal principal components (PCs) using principal component analysis (PCA). Following these criteria, 64 predictors (current and prior year ring index as a predictor) were retained for reconstruction. The resulting time series from PCA entered into the regression against the instrumental PDSI data.

Because the common usable chronology length of the current network is $1852-1982$, a nesting procedure was used to extend the length of the drought reconstruction (Meko 1997; Cook et al. 2003). Through this procedure, shorter chronologies are dropped as potential predictors through an iterative process and new reconstruction nests are created beyond the common period. Twenty "backward nests" were created for our drought reconstruction. Similarly, "forward nests" were created for the time between 1981 and 2004 by dropping chronologies collected after 1981 but before more recent collections; 2004 is the last year of collections by this laboratory in the Hudson Valley. A total of six forward nests were created using chronologies from the 19822004 period. The reduction of error (RE) and coefficient of efficiency (CE) statistics were used to verify model skill of all backward and forward reconstruction nests. Positive RE and CE values indicate predictive skill (Fritts 1976; Wigley et al. 1984; Cook et al. 1994).

The reconstruction here was built upon the 1895-1981 period, which is the common period between all chronologies and the instrumental data. Investigation into the stability of all reconstruction nests was conducted through two split calibration-verification tests. The meteorological data were split into one-third and two-third portions for the first calibration-verification test and then reversed for the second set of calibration and verification tests (supplemental Table S2). Additional years of meteorological data gained through forward nesting (because of an increased common period of more recent years between tree-ring records and meteorological data) were used in the development of the reconstruction as well as all calibration-verification tests. Any reconstruction nest that accounted for less than $30 \%$ of the annual drought variation from the instrumental record or any test that produced negative RE and $\mathrm{CE}$ statistics were considered insufficient for reconstruction and omitted from the final reconstruction.

\section{c. Assessing historical hydroclimate variability}

Drought and pluvial events were quantified and ranked following Gray et al.'s (2011) adaptation of Biondi et al. (2002, 2005), except that we focus only on drought and pluvial events of three or more consecutive years to examine extended events. We calculated the duration or length, the magnitude (sum of the departure values from the median) and intensity (sum of the departure values from the median divided by the duration) of each run. Each drought and pluvial event is ranked, where the larger the departure from the median or the greater the intensity of the event, the lower the event is initially ranked. The magnitude and intensity value ranks for each event are then added together. Events with the largest combined score are considered more severe.

\section{d. Assessing species contributions to hydroclimatic reconstructions}

We calculated the relative explained variance of each species to investigate the value of each to the reconstruction following Frank and Esper (2005). Absolute values of beta weights, or the standard regression coefficient that represents predictor loading in principal component regression analysis, were summed for each chronology when the current year's $(t)$ and previous year's growth $(t+1)$ passed predictor selection criteria. The summed value for each chronology was divided by the sum of all beta weights and then again by 100. For species with multiple chronologies (eight species), minimum, maximum, and average relative variance explained (AREV) was also calculated. Our analysis is intended to further explore the importance of species replication, chronology replication and chronology quality in dendroclimatic research. Investigation of all permutations of 12 species and 32 chronologies is beyond the scope of this 


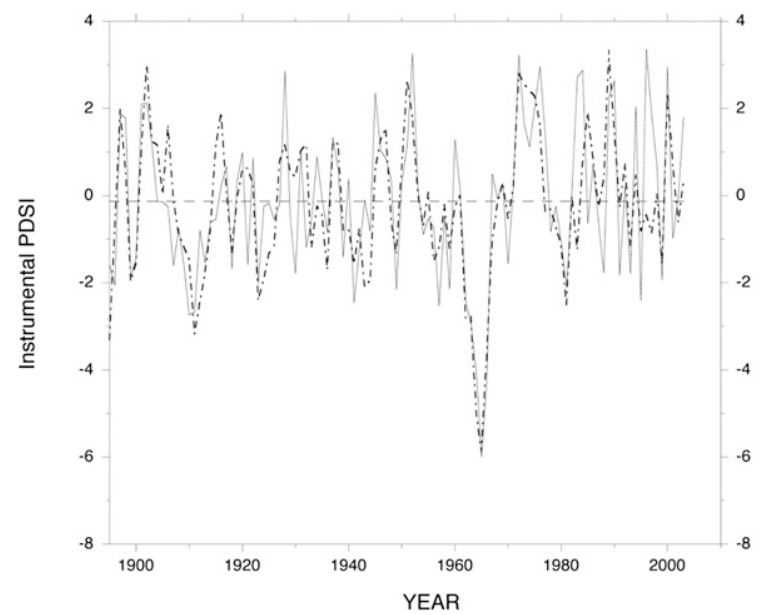

FIG. 2. Tree ring reconstruction (dash-dot line) vs average MayAugust instrumental PDSI (solid line) over the common period from 1895 to 2002. Supplemental Table S2 contains calibrationverification statistics for all nests.

paper and is therefore limited to a few ranges of species replication, chronology replication and chronology quality. Chronology quality for this purpose is defined as the annual variance accounted for by each chronology of the instrumental data being reconstructed. Where there are duplicate chronologies for a species, each chronology is ranked by the amount of annually accounted variance with the highest (lowest) amount of variance considered the "best" ("worst") (see Table 2).

\section{Results}

\section{a. Reconstruction modeling and spatial representation}

Ring width variation for the common period between all tree-ring records and the instrumental PDSI data (1852-1981) accounted for $66.2 \%$ of the annual variation of average May-August PDSI (Fig. 2; supplemental Table S2). Most nests reconstructing hydroclimate before 1852 account for nearly $50 \%$ of annual variation in instrumental PDSI (i.e., $r^{2}$ for the 1602-61 nest $=$ $49.6 \%)$. By our criteria, the $1515-30$ nest fails when it accounts for only $26.9 \%$ of the annual variance in the instrumental record. The first usable nest is the 1531-56 nest, which accounts for $44.1 \%$ of the annual average of May-August instrumental PDSI between 1895 and 1981. Going forward past 1981 and up to the 2002 nest, tree rings account for $49.3 \%$ or more of instrumental PDSI. The 2002 nest, composed of only four chronologies, accounts for $33.8 \%$ of annual drought variation while the 2003 nest accounts for $31.5 \%$ (supplemental Table S2). RE and CE statistics are positive for all nests between 1531 and 2002, although verification RE and

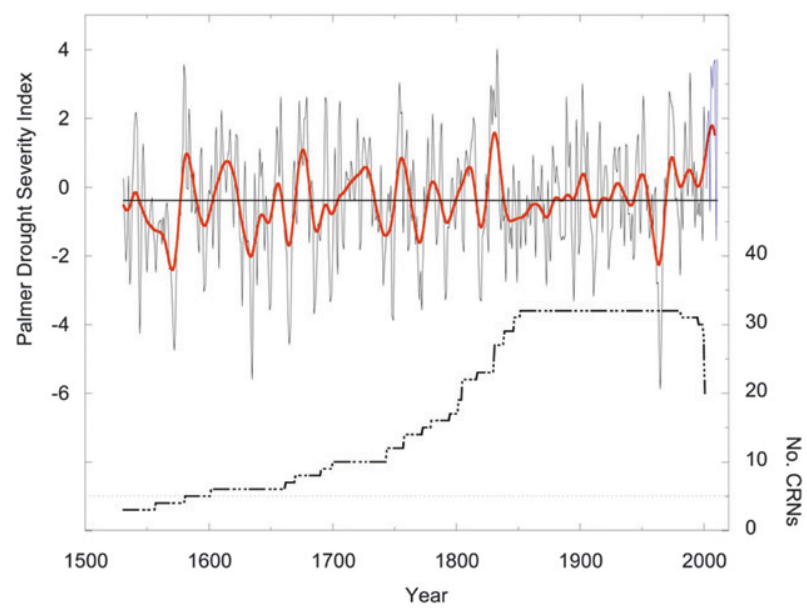

FIG. 3. Drought history of the NYC watershed region from 1531 to 2011. The orange, smoothed line is a 20 -yr spline while the flat, black line represents the long-term median. Instrumental data during 2004-11 (in blue) is tacked onto the end of the tree-ringbased reconstruction (1531-2004). The thick, dot-dash line in the bottom of the figure represents the number of chronologies through time. The dashed-gray line highlights replication at five chronologies.

CE both drop below 0.100 for the 1999 and 2000 nests indicating a weakening of skill. Meteorological data are added after 2003 so that the final reconstruction of drought in the NYC watershed covers 1531-2011 (Fig. 3).

The use of novel species for drought reconstruction appears to have improved model skill. While more commonly used species like Juniperus viginiana, Quercus alba, Quercus montana and Tsuga canadensis have high AREV, novel species had among the highest amounts of relative variance explained (Table 1). Liriodendron tulipifera had the second highest AREV (5.31), just behind Tsuga canadensis (5.69). Similarly, Carya glabra performed nearly as well as Juniperus viginiana (AREV = 4.05 versus 4.39 , respectively) and Betula lenta performed

TABLE 1. Rank of species used here to reconstruct past drought based upon their average relative explained variance (AREV). See text for calculation details.

\begin{tabular}{lcccc}
\hline \multicolumn{1}{c}{ Species } & No. CRNs & Avg AREV & Min AREV & Max AREV \\
\hline T. canadensis & 3 & 5.69 & 2.98 & 7.38 \\
L. tulipifera & 3 & 5.31 & 2.42 & 7.15 \\
J. virginiana & 1 & 4.39 & - & - \\
C. glabra & 3 & 4.05 & 2.59 & 4.95 \\
Q. stellata & 1 & 3.72 & - & - \\
B. lenta & 2 & 3.38 & 2.59 & 4.17 \\
P. rigida & 1 & 2.87 & - & - \\
Q. montana & 5 & 2.82 & 0.06 & 5.29 \\
Q. rubra & 4 & 2.38 & 1.30 & 4.00 \\
Q. alba & 5 & 1.75 & 0.68 & 2.48 \\
Q. velutina & 3 & 1.39 & 1.38 & 1.52 \\
C. ovata & 1 & 0.62 & - & - \\
\hline
\end{tabular}


TABLE 2. Comparison of various combinations of species replication, chronology replication, and chronology quality ranked by $r^{2}$. The end of the table compares reconstruction statistics for chronologies for more commonly used species (Traditional) vs new or infrequently used species to dendroclimatology (Novel). We compare the same season and time period (1895-1981). CRNs = chronologies; Spp = species; Dup $=$ duplicated species or species with more than one chronology; $\mathrm{B}=$ best; $\mathrm{W}=$ worst; Trad. $=$ traditional species. Phrases like "All Spp., Dup. B/W" means that the mix of chronologies is represented by all 12 species with species having more than one chronology represented by the best and worst chronology. "Dup. B/W" means that all duplicated species are represented by their best and worst chronologies. Phrases like "B Spp" means the best species in terms of their explained variance. If followed by "B" or "W," they are comprised only of the best or worst chronologies. Finally, "8 B CRNs" simply means the best chronologies according to their individual $r^{2}$ to the instrumental data.

\begin{tabular}{|c|c|c|c|c|c|c|c|c|c|c|c|c|c|}
\hline \multirow[b]{3}{*}{ Mix (No. CRNS) } & \multirow{3}{*}{$\frac{r^{2}}{1895-1981}$} & \multicolumn{4}{|c|}{ Pearson $r$} & \multicolumn{4}{|c|}{$\mathrm{RE}$} & \multicolumn{4}{|c|}{$\mathrm{CE}$} \\
\hline & & \multicolumn{2}{|c|}{$1895-1924$} & \multicolumn{2}{|c|}{$1925-81$} & \multicolumn{2}{|c|}{ 1895-1924 } & \multicolumn{2}{|c|}{$1925-81$} & \multicolumn{2}{|c|}{ 1895-1924 } & \multicolumn{2}{|c|}{$1925-81$} \\
\hline & & Calib & Veri & Calib & Veri & Calib & Veri & Calib & Veri & Calib & Veri & Calib & Veri \\
\hline All Spp. & 66.4 & 0.758 & 0.788 & 824 & 0.716 & 0.575 & 0.552 & 0.680 & 0.423 & 0.575 & 0.517 & 0.680 & 0.412 \\
\hline All Spp. \& CRNs (32) & 66.2 & 0.717 & 0.781 & 0.844 & 0.722 & 0.515 & 0.487 & 0.712 & 0.405 & 0.515 & 0.485 & .712 & 0.395 \\
\hline Dup. B/W (16) & 61.4 & 0.709 & 0.744 & 0.813 & 0.626 & 0.503 & 0.514 & 0.661 & 0.304 & 0.503 & 0.509 & 0.503 & 0.292 \\
\hline All Spp., Dup. W (20) & 60.4 & 0.725 & 0.730 & 0.782 & 0.673 & 0.525 & 0.444 & 0.611 & 0.271 & 0.525 & 0.438 & 0.611 & 0.258 \\
\hline 8 B Spp, B (8) & 58.4 & 0.697 & 0.709 & 0.817 & 0.442 & 0.485 & 0.411 & 0.668 & 0.133 & 0.485 & 0.384 & 0.668 & 0.118 \\
\hline Trad. Spp. (16) & 58.3 & 0.765 & 0.767 & 0.787 & 0.743 & 0.585 & 0.480 & 0.620 & & 0.585 & 0.474 & 0.361 & 0.349 \\
\hline 10 B Spp, B (10) & 57.6 & 0.742 & 0.766 & 0.828 & 0.578 & 0.550 & 0.489 & 0.686 & 0.254 & 0.550 & 0.475 & 0.686 & 0.253 \\
\hline All Spp., B (12) & 56.6 & 0.762 & 0.764 & 0.835 & 0.568 & 0.581 & 0.484 & 0.697 & 0.239 & 0.581 & 0.470 & 0.697 & 0.238 \\
\hline 8 B CRNs (8) & 54.6 & 0.705 & 0.661 & 0.781 & 0.533 & 0.497 & 0.380 & 0.610 & 0.243 & 0.497 & 0.351 & 0.610 & 0.230 \\
\hline 3 Trad. Spp, 2 B ea (6) & 53.5 & 0.722 & 0.641 & 0.737 & & 0.521 & 0.374 & 0.543 & 0.227 & 0.521 & 0.345 & 0.543 & 0.214 \\
\hline All Spp., W (12) & 49.4 & 0.771 & 0.624 & 0.716 & 0.622 & 0.594 & 0.356 & 0.513 & 0.177 & 0.594 & 0.350 & 0.513 & 0.163 \\
\hline 10 B CRNs (10) & 48.6 & 0.708 & 0.683 & 0.816 & 0.544 & 0.501 & 0.393 & 0.666 & 0.224 & 0.501 & 0.365 & 0.666 & 0.211 \\
\hline 8 W Crns (8) & 38.9 & 0.661 & 0.500 & 0.639 & 0.504 & 0.436 & 0.256 & 0.408 & 0.168 & 0.436 & 0.248 & 0.408 & 0.153 \\
\hline 8 W Spp, W (8) & 35.8 & 0.726 & 0.520 & 0.638 & 0.521 & 0.527 & 0.266 & 0.408 & 0.151 & 0.527 & 0.258 & 0.408 & 0.137 \\
\hline Traditional & 58.3 & 0.765 & 0.767 & 0.787 & 0.743 & 0.585 & 0.480 & 0.620 & 0.361 & 0.585 & 0.474 & 0.620 & 0.349 \\
\hline Novel & 58.4 & 0.642 & 0.622 & 0.801 & 0.416 & 0.413 & 0.320 & 0.641 & 0.138 & 0.413 & 0.294 & 0.641 & 0.129 \\
\hline
\end{tabular}

nearly as well as Quercus stellata (AREV $=3.38$ versus 3.72, respectively). Quercus alba and Quercus montana AREV values are lower than one might expect given their usefulness in previous reconstructions. This is mainly due to the use of a chronology of each species that is relatively weak. For example, four of the five Quercus montana chronology AREV values are $>2.9$ with a maximum value of 5.29. In comparison, the weakest Quercus montana AREV value is 0.06 (Table 1). A similar situation is seen with Quercus rubra. Three of the four chronologies here have AREV $>2.1$ while the weakest chronology has an AREV of 1.3. We also investigated the efficacy of these novel species by comparing calibration and verification statistics for the 1895 1981 common period between "traditional" and novel species (Table 2). Novel species perform nearly as well on their own when reconstructing average May-Aug instrumental PDSI as the traditional species.

Despite the often observed limitations of tree-ring data to effectively capture wet years and pluvial events (Fritts 1976), the tree-ring network here captures wet years and pluvial events within the instrumental record nearly as well as drought events (Fig. 2). It should be noted that two of the three pluvial events after 1981 are not captured as well, which could limit the interpretation of reduced pluvial events during the prior four centuries (discussed below). However, the tree ring based reconstruction indicates wet conditions or captures the event pattern for $64.3 \%$ of the 14 pluvial events in the instrumental record above the 1895-2011 median $\geq 2$ years in duration $(1897 / 98,1901-03,1916 / 17,1919 / 20$, 1927/28, 1937/38, 1945-48, 1950-53, 1960/61, 1967-69, 1971-77, 1982-84, 1989/90, 1996-98). Two of the five events where the tree rings underperform (1982-84 and 1996-98) are well above the median. The remaining pluvial events are smaller excursions from the median. This underperformance could be the result of reduced replication, the network being dominated by dendroecological collections, or time-varying standardization. It would seem the most important factor here is the time-varying standardization. First, chronology replication only drops from 32 to 28 chronologies by 2000. Next, our results actually indicate that reduced chronology replication is less of a problem if species replication is higher (Table 2). Species replication in the tree-ring network after 1981 is still high. Finally, a new study (Pederson et al. 2012b) supports an earlier postulation that site selection might matter less when sampling for hydroclimatic reconstructions in the eastern United States (Cook 1982). The new study indicates that randomly-selected trees, even those from mesic environments, reflect annual to decadal hydroclimatic variation 
over the prior two centuries. So, it seems less likely that the use of dendroeclogical collections is the cause of weaker performance during the 1996-99 pluvial event. Given this evidence and the fact that these events were within the last decade of the tree-ring based reconstruction, it seems that time-varying standardization methods might be the primary reason for the underperformance during two of the last three pluvial events. Time-varying standardization reduces the amount of medium-frequency variation at the ends of time series (Melvin and Briffa 2008). In our network, there are only a few periods when multiple chronologies line up in a way so that a loss of medium frequency at the end of a time series could be compounded to underestimate hydroclimatic variation. These periods are: 1660-1700, 1740-60, 1795-1810, 1830-50, and after 1992. We do note that the sign tests for both calibration-verification tests were highly significant $(26+/ 4-, z$ score: $3.834, p$ level $=$ 0.00006 for 1895-1924 calibration period; 44+/13-, $z$ score: $3.974, p$ level $=0.00004$ for the $1925-81$ calibration period) indicating a strong ability of the network to capture wetter and dryer years and events. Most of the wet years and multiannual pluvial events in the instrumental record are captured by the composite tree-ring record.

Not only does the new reconstruction of PDSI represent the NYC watershed, it also represents regionalscale precipitation. Between 1901 and 2006 our reconstruction correlates significantly with April-July precipitation across the northeastern United States and southern Canada, with average May-July precipitation providing the strongest correlation (supplemental Fig. S3). The correlation is strongest $(r \geq 0.50)$ across the northern mid-Atlantic region. The strong relationship with growing-season precipitation provides independent evidence that the reconstruction presented here represents hydrometeorological conditions over a significant portion of the northeastern United States.

\section{b. Hydroclimate variability over the last five centuries}

The new reconstruction indicates that the 1960s drought remains the most intense drought experienced by the region over the last 481 years (Figs. 3 and 4; supplemental Table S3); only the 7-yr droughts starting in 1630 and 1661 approach the 1960s in overall intensity. However, the new drought record shows that seven drought events exceed the duration of the 6-yr, mid-1960s drought. All but one of these extended droughts occurred prior to the twentieth century. The average drought event length for the entire record is 5.2 years, while the average drought event duration for the twentieth century is marginally less at 4.8 years. Most importantly, only two drought events of 3-years or more in length occurred after 1967 (Fig. 4). Over the entire

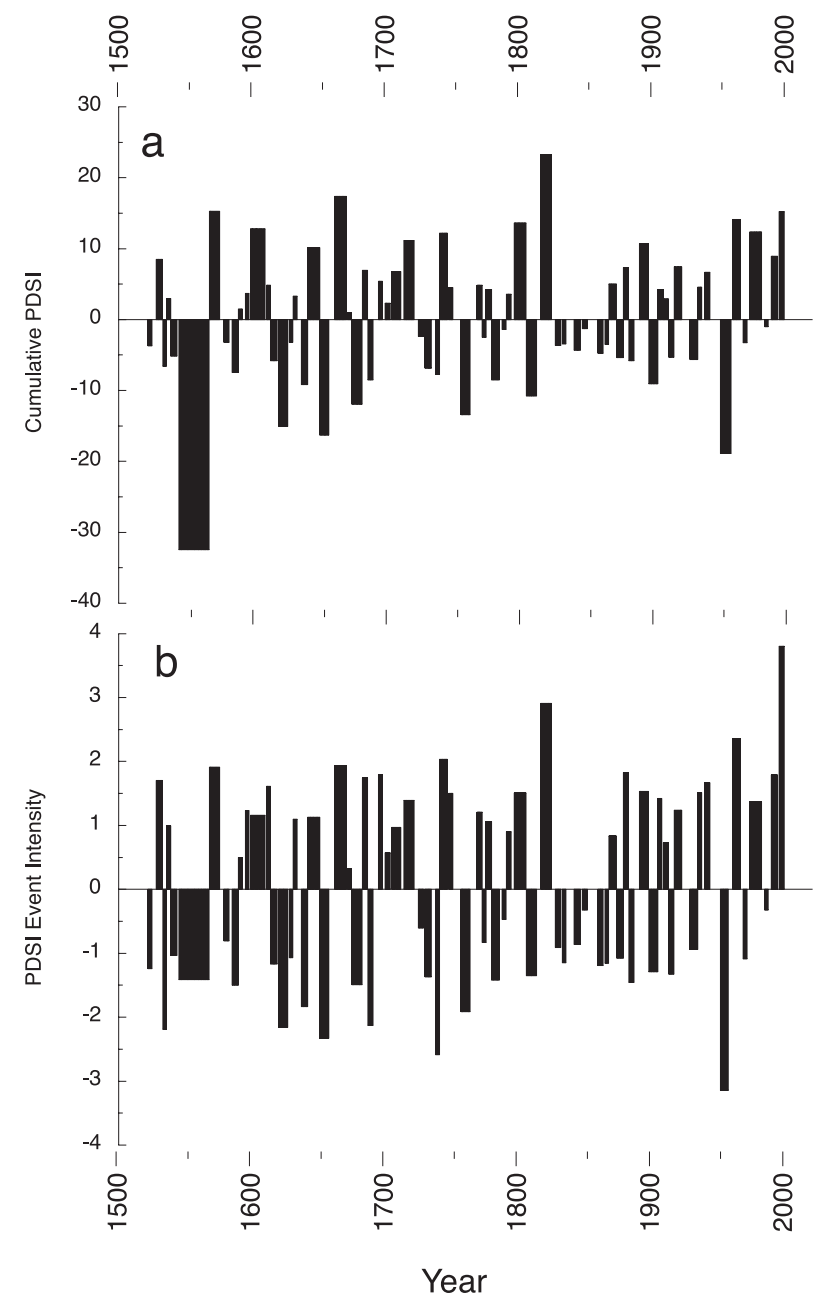

FIG. 4. Temporal distribution of (a) magnitude and (b) intensity of pluvial and drought events 3 years or more in duration. Magnitude portrays the cumulative severity of each event while the intensity indicates the average severity of each event. See text for more details.

record, the seventeenth century appears to have been the most prone to frequent, high severity droughts (supplemental Table S3). Yet, the most striking drought era occurs in the mid-sixteenth century when a 23-yr drought beginning in 1555 (ranked 6th) occurs only 1 year after a 5-yr drought event (ranked 24th) and a decade after the 10th ranked drought that began in 1543 (Fig. 4). Only four positive departures from the long-term median, representing moister conditions, occur between 1543 and 1577. While 1960s drought still stands out as significant in the new 500-yr record, the sixteenth and seventeenth centuries are dry centuries.

What might be most striking about the new reconstruction, however, is the upward trend toward pluvial conditions since the early-nineteenth century (Figs. 3 and 4; supplemental Table S4). Only the 1960s drought interrupts this multicentennial trend. The multicentennial 

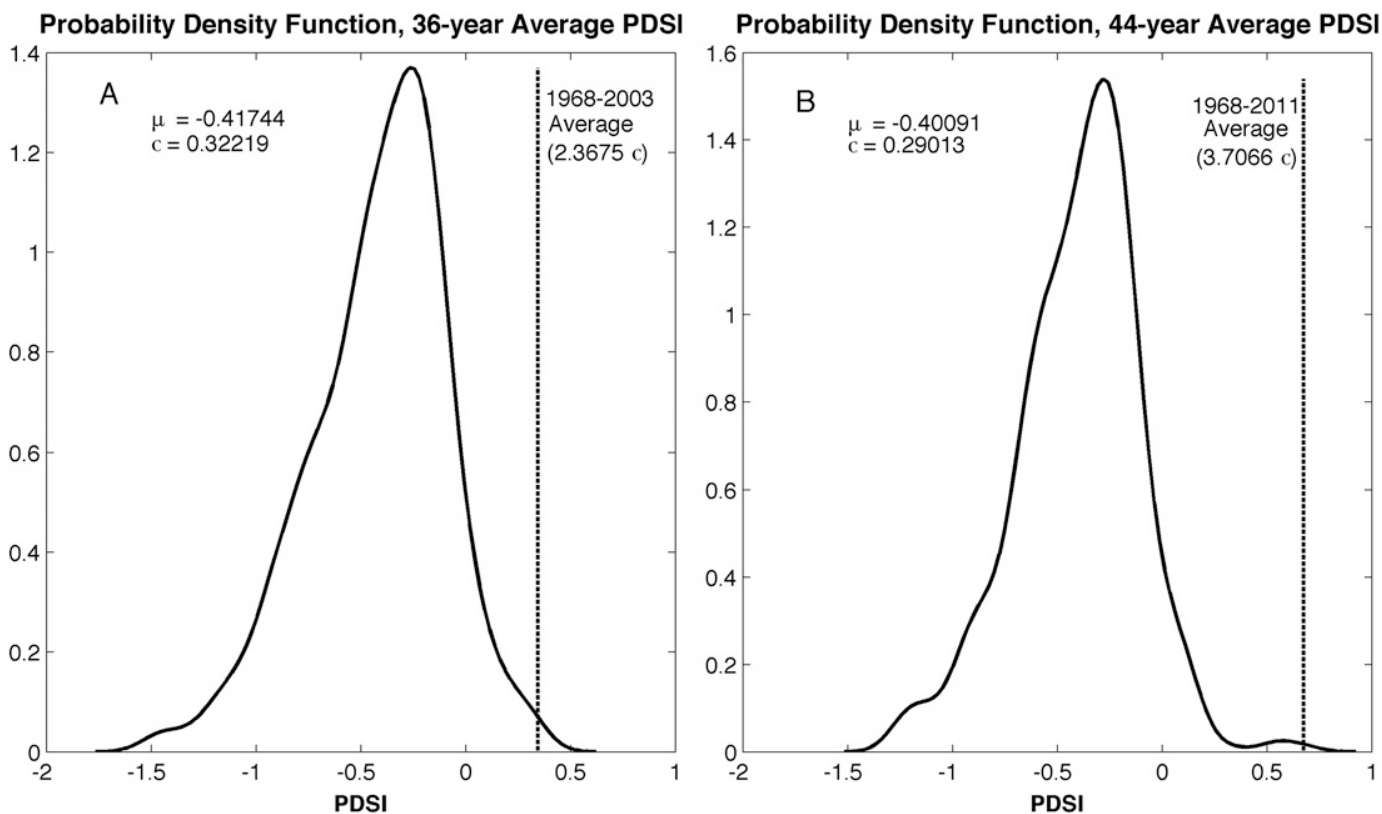

FIG. 5. Probability distributions of (a) 35-yr period within the tree-ring based reconstruction from 1531 to 2003 and (b) 44-yr periods within the entire 1531-2011 record. The vertical lines represents 1968-2003 and 1968-2011 averages, respectively.

trend is punctuated by a series of intense pluvial events after 1967. Two of the top four highest-ranked pluvial events occur between 1971 and 2009 (supplemental Table S4). In fact, 7 of the 20 highest-ranked pluvial events have occurred since 1901. The 2006 and 1971 pluvial events represent high and extreme soil moisture conditions (average PDSI $=2.36$ and 3.80, respectively). Averaged over the 1968-2011 period, PDSI has a value of 0.67 despite including 12 negative years and from 2000-11 has an average of 1.67 despite including 2 negative years. The top two recent pluvial events are only rivaled by the 8 -yr pluvial beginning in 1827 , the 9-yr pluvial beginning in 1672, and the 8 -yr pluvial beginning in 1578 (supplemental Table S4). While the duration of positive soil moisture conditions in the most recent pluvial events has been exceeded historically, the predominantly pluvial PDSI conditions since the beginning of the twenty-first century are virtually unrivaled in terms of intensity.

To demonstrate this more clearly, we first look at the most recent decades of the reconstruction. The 35-yr period from the end of the 1960s drought up to the end of the tree-ring portion of the reconstruction (2003) stands out as a significantly wet era, with a mean $\sim 2.4$ standard deviations above that of all other 35 -yr periods in the reconstruction (Fig. 5a). This alone marks the postdrought period as anomalous. However, the years since the end of our reconstruction have been wetter still, standing out as a distinct regime (Fig. 1b and supplemental
Fig. S1). We would expect reconstructions from tree-ring chronologies updated to 2011 to exhibit similar jumps in ring width, but we do not yet have data to verify this shift. We can get some sense of how anomalous the period since the end of the 1960s drought is by adding the most recent 9 years of instrumental data onto the end of the reconstruction (Fig. 5b). This period then stands out at around $\sim 3.8$ standard deviations above the average of all other 43-yr periods within the reconstruction. To determine if this arbitrary or more ad hoc analysis might have induced some bias, we conducted a continuous analysis to examine how the post-1960s drought era fits in the probability distribution of the last 500 years. Results support the idea that the current pluvial era is anomalous (supplemental Fig. S4). As the tree-rings are providing a reflection of most pluvial events in the instrumental record (Fig. 2), we can be pretty sure that the last three to four decades in the New York City watershed have been some of the wettest experienced in the last 500 years.

\section{Discussion}

The new reconstruction of drought for the NYC watershed highlights two important aspects of regional hydroclimatic history. First, while the 1960s drought is still among the most intense droughts over the last 500 years, it interrupts a multicentennial trend of increasing moisture availability that has continued through 2011. Second, the new record gives greater insight 


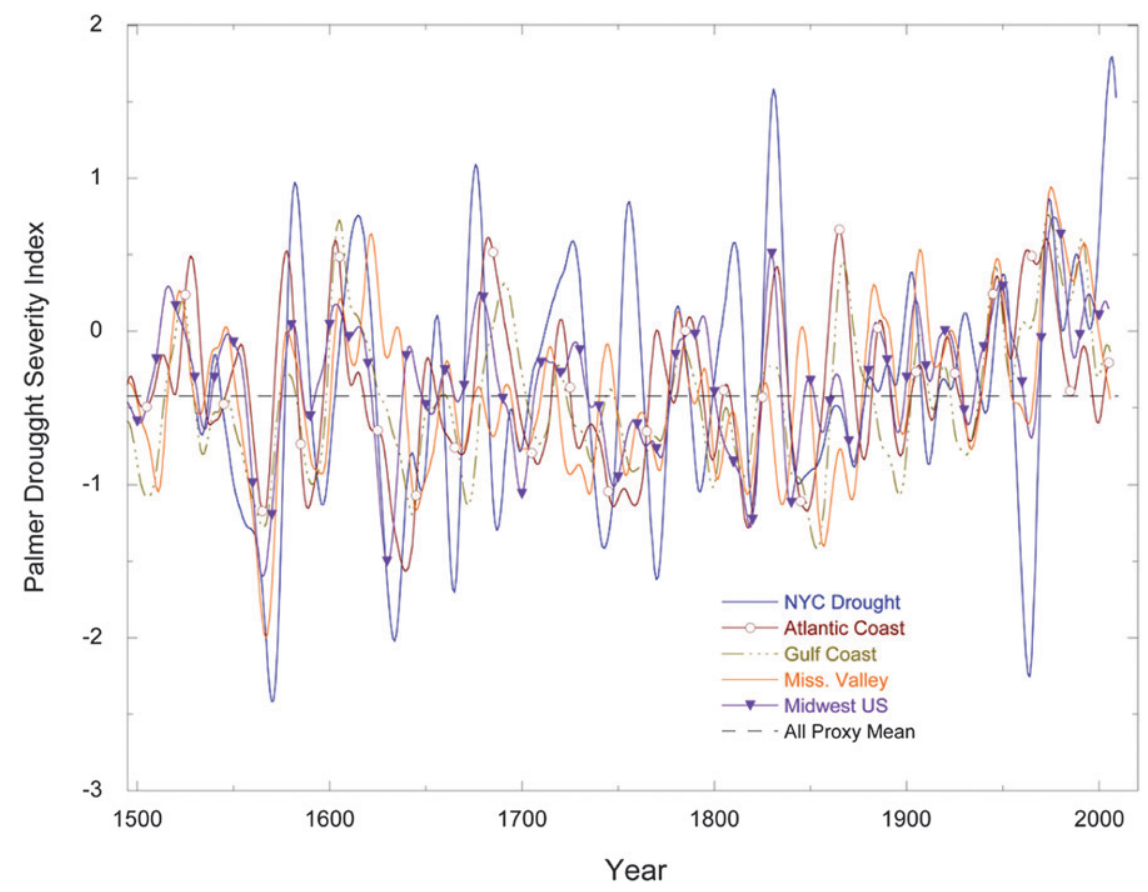

FIG. 6. Five records of hydroclimate variability across the eastern United States. The new NYC drought reconstruction now provides evidence that the sixteenth century megadrought (Stahle et al. 2000) extended up into the northeastern United States and that the trend toward more pluvial conditions is present in five independent records across much of the eastern United States. Each line is a 20 -yr spline of the each annual record. The dashed line is the mean of each record's mean.

regarding the spatial extent and severity of the megadroughts during the 1500s and provides greater temporal and spatial insight into droughts during the 1600s. Two other important outcomes of this work are that 1) an improved depiction of historical droughts and the long-term trend of increasing moisture availability should be useful for understanding the complex climate dynamics in the eastern United States and 2) the reconstruction's strength appears to be partly derived from high tree species replication. We will detail the implications of the regional hydroclimatic history, methodological aspects of the tree-ring based NYC watershed reconstruction, and its potential societal impacts in the following sections.

\section{a. Multicentennial trend toward pluvial conditions}

One of the most prominent trends in the NYC watershed reconstruction is the general trend toward pluvial conditions since ca. 1800. The magnitude of drought events after the 1827 pluvial is less than in prior centuries and becomes nearly nil after the 1960s drought (Fig. 4a). Perhaps as striking is the trend of reduced drought intensity since the late eighteenth century (Fig. 4b). The trend of increasing pluvial conditions is not limited to the NYC watershed region either; instead, it appears to be a local expression of a broader hydroclimatic change across the eastern United States (Fig. 6). Independent analyses have indicated wetter conditions since the late nineteenth and early twentieth centuries in three separate regions (Stahle et al. 1988; Stahle and Cleaveland 1992, 1994; E. R. Cook et al. 2010; McEwan et al. 2011). Here we show that the recent trend of increased wetness in the NYC watershed generally matches five regionallydistinct, tree-ring records of paleodrought drawn from the NADA. Much of the eastern United States has been unusually and somewhat persistently wet since the late 1800s. Almost all of these records indicate more pluvial conditions since the late 1950s. The only event that stands out from this large-scale pattern of change is the unusually severe 1960 s drought. Since that event, our reconstruction indicates that this region of the northeastern United States has been experiencing the strongest pluvial conditions in the eastern United States.

The instrumental record further supports our finding that recent pluvial events in the NYC region are at the upper limit of hydroclimatic variability for the last 500 years. Even though the 2006-09 pluvial is virtually unrivaled, 2011 goes beyond the 2006-09 event: the 2011 May-August average PDSI value is 3.72, including a value of 5.64 for August. The August 2011 PDSI value is the highest instrumental calculation for any month 


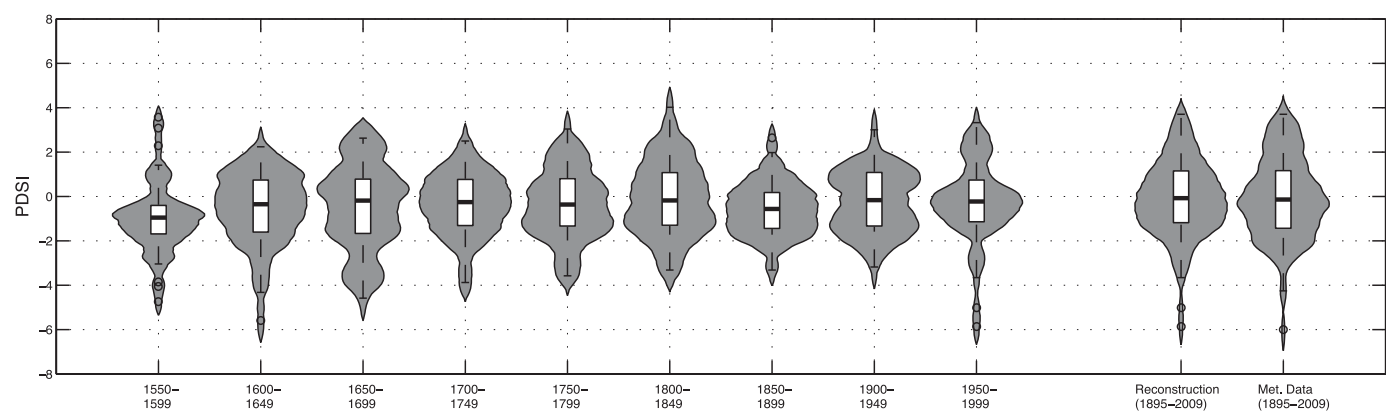

FIG. 7. Violin plots for 50-yr segments from 1550 to 1999 and for the 1895-2003 common period of the reconstructed and meteorological data, showing data quartiles and outliers (box-and-whisker plots) and probability densities (shaded gray areas).

since 1895 . Further, the only monthly PDSI values in the instrumental record greater than 5.0 occur after $2003(n=$ 4). And, of the 20 highest monthly PDSI instrumental values, only one occurred prior to 1975 (a value of 4.48 in October 1955 ) - $70 \%$ of the 20 wettest months occur after 2000. Both paleo- and instrumental records point out that the recent decade of pluvial conditions is at the upper end of hydroclimatic variability over the last 100 and 500 years (Figs. 1 and 5), which likely accounts for the lack of water emergencies since 2002. Taken at face value, all these data suggest the long-term trend in pluvial conditions is unusual over the last 500 years.

The long trend toward today's pluvial conditions in the NYC watershed matches patterns in other parts of the Northern Hemisphere. Notably, increasing and sustained trends in precipitation or pluvial conditions are seen in Bavaria (Wilson et al. 2005), northeastern China (Sheppard et al. 2004), northwestern China (Li et al. 2006; Yin et al. 2008; Zhang et al. 2011), southern England (Büntgen and Tegel 2011), western Mongolia (Davi et al. 2009), Pakistan (Treydte et al. 2006), and the central Rocky Mountains (Knight et al. 2010); trends for northern or "High" Asia are summarized and shown to be occurring most strongly in the west, with no such trend in monsoonal Asia (Fang et al. 2010). Interestingly, reconstructions at lower latitudes and in some semiarid regions are trending toward drought after wetter twentieth centuries, including Mexico (Cleaveland et al. 2003), eastern and central Mongolia (Pederson et al. 2001; Davi et al. 2006), western Turkey (Akkemik et al. 2005; Touchan et al. 2007; Köse et al. 2011), southeastern United States (Pederson et al. 2012a), western United States (Cook et al. 2004; Woodhouse et al. 2005, 2010), and southern Vietnam (Buckley et al. 2010). Abrupt decreases in precipitation are more likely to occur in semiarid and arid regions (Narisma et al. 2007). So, the opposite trend toward pluvial conditions in the perhumid NYC region mirrors patterns seen in more mesic regions of the Northern Hemisphere.

\section{b. Severity and spatial extent of historical megadroughts}

The hydroclimatic reconstruction for the NYC watershed reveals significant drought events between 1500 and 1700 . We now have evidence that the sixteenth century megadrought (Stahle et al. 2000) extended into the northeastern United States (Figs. 4 and 6). Outside of the Niagara Escarpment records in southern Canada (Buckley et al. 2004), few records are able to convey information regarding the sixteenth century megadrought for the region. For the northeastern United States, the sixteenth century megadrought is unprecedented over the past five centuries (Fig. 7). No other century contains a drought 23 years in duration immediately following two intense droughts (Fig. 4). While the new record here fills an important space concerning the spatial extent of the sixteenth century megadrought, it is now apparent that the sixteenth century megadrought is the most coherent drought episode across the eastern United States over the last 500 years (Fig. 6).

Not to be overlooked, however, are the severe and frequent seventeenth century droughts. While not having nearly 40 years of sustained drought, the seventeenth century has six significant droughts after 1632 (Fig. 4). Importantly, the new reconstruction indicates the 1633 drought to be of the same magnitude as the 1960s drought (Fig. 4a). What is different about the two halfcenturies in which these significant droughts occur is that the first half of the seventeenth century contains a greater proportion of drought than the late twentieth century (Fig. 7). Further revealing the aridity of the seventeenth century is the fact that the latter half of the seventeenth century has a greater density of overall drought likelihood than the first half of the seventeenth century making the seventeenth century one of the driest over the last 500 years (Fig. 7). Our new record also indicates that the 1661-67 drought is more severe (average PDSI $=-2.33$ ) than that currently portrayed in NADA (supplemental 
Fig. S4) and an investigation of North American drought to the west of our network (Fye et al. 2003). The seventeenth century now appears to be a period plagued with frequent and intense droughts.

While the sixteenth century megadrought is well known in the paleoclimatological record, the mid-seventeenth century drought has been primarily documented in other geologic proxies to the west and northwest of our study region (Bégin and Peyette 1988; Wolin 1996; Lichter 1997; Nielsen 1998; Loope and Arbogast 2000; Argyilan et al. 2005; Shuman et al. 2009). Only recently was the severity of drought during the seventeenth century highlighted in close proximity to our study region (Nichols 2010; Ireland and Booth 2011). The NYC watershed reconstruction fills in a spatial gap of these records and adds greater temporal detail throughout the seventeenth century. As the dendroclimatological record of drought is pushed further back in time, more precise temporal resolution is revealed for severe droughts like that in the seventeenth century.

The high-resolution revelation of severe and frequent droughts in this region prior to 1700 is important. Previously, the most serious drought was the 1960s drought (Cook and Jacoby 1977; Lyon et al. 2005; Devineni et al. 2013), a drought that NYC adapted to and survived. However, the great frequency of droughts nearly severe as the 1960s drought during the seventeenth century and the overwhelming magnitude of the 23-yrlong sixteenth century should put political and resource management agencies in the NYC metro region and the greater megalopolis region (supplemental Fig. S3) on notice: the northeastern United States is not a region without severe droughts. In fact, a high-resolution sediment-core record reaching back to ca. 500 in the lower Hudson Valley indicates that the sixteenth and seventeenth century droughts are not the worst that this region could experience (Pederson et al. 2005).

\section{c. Contribution to climate dynamics}

The new information on the spatiotemporal patterns of drought in the northeastern United States will inform modeling efforts attempting to understand the drivers of climate dynamics for North America. The trend toward highly unusual conditions in the paleo- and instrumental records in the last 40 years might be reflections of abrupt climate change. Significant, positive trends in heavy precipitation, wetness, streamflow and soil moisture have been identified in the eastern United States during the twentieth century (Kunkel et al. 1999; Easterling et al. 2000; Groisman et al. 2004; Hodgkins and Dudley 2011). The northeastern portion of the United States has, in fact, some of the strongest trends in precipitation intensity, frequency and extreme events (Karl and Knight 1998;
Karl et al. 2009; Brown et al. 2010; Min et al. 2011). The increase in pluvial conditions and a new regime in the instrumental record since 2003 (Figs. 1 and 3-6 and supplemental Fig. S1) only continues trends identified in previous studies.

The causes of a shift to a wetter climate in the northeast are difficult to discern (e.g., Seager et al. 2012). Precipitation variations in the region have been linked to variability of the storm tracks over North America and the North Atlantic Ocean (Seager et al. 2012) and also to variations in the position and strength of the Atlantic subtropical high (Stahle and Cleaveland 1992; Davis et al. 1997; Hardt et al. 2010; Seager et al. 2012), although the mechanisms for variations of the high are unclear. While the NYC watershed drought reconstruction is significantly and positively correlated to January sea surface temperatures from 1948 to 2011 (supplemental Fig. S6), these patterns resemble those forced by the atmospheric flow anomalies and seem to be unlikely to have actually caused the atmospheric flow anomalies that control precipitation variations (Seager et al. 2012). There is an apparent association of our reconstruction with the northern Atlantic Ocean from January through March (supplemental Fig. S5). However, a correlation from 1531 to 2001 between the NYC warm-season reconstruction and a winter NAO reconstruction (Cook et al. 2002) shows virtually no correlation $(r=0.14)$. There is also an association with the eastern Pacific Ocean in February that fades by April (supplemental Fig. S5) and correlation in March that suggests a link to the Gulf Stream; the Gulf Stream association is similar to a finding in Joyce et al. (2009). Regardless, the causes of the recent hydroclimatic variability remain poorly known and are possibly complex and multifaceted. Immediately after the 1960s drought it was observed that the event was likely the result of "multiple and interlocking causes" (Namias 1966, p. 553). A search for the causes of droughts and pluvials in the NYC region will require careful attention to human-induced climate change, nonlinearities or asymmetries in the climate system (Gong et al. 2011), the interaction between multiple, large-scale climate systems over the northeastern United States (Archambault et al. 2008; Budikova 2008), and the influences of a variety of modes of climate variability including ones that are not forced by the ocean (see B. I. Cook et al. 2010).

\section{d. Implications for tree-ring reconstructions in humid regions}

As expected by inference (García-Suárez et al. 2009; Cook and Pederson 2011) and evidenced in application (Maxwell et al. 2011), increased species replication appears to improve reconstruction models (Table 2). From 
the exploration of the influence of chronology replication, chronology quality and species replication on treering based reconstructions, it is interesting to note the following: 1) a reconstruction composed of only the best and worst chronologies of duplicated species (two chronologies/species for a total of 16 chronologies) or all species allowing for only the worst two chronologies of duplicated species $(n=20)$ performed nearly as well as the full network $(n=32) ; 2)$ a reconstruction composed of the best chronology from the 10 best species outperforms the best 10 overall chronologies; and 3) the best chronology from the eight best species $(n=8)$ performs nearly as well as using all chronologies from traditional dendroclimatological species in the region $(n=$ 16) (Table 1). Results here suggest that species replication is important in reconstructing hydroclimate in humid, closed-canopy environments.

With the on-going functional extinction of Tsuga canadensis (Orwig and Foster 1998; Bonneau et al. 1999; Orwig et al. 2008), one of the most important tree species for paleoclimatic research in eastern North America, and the expected increase in the loss of tree species, it is important to identify other species that could replace climatically-sensitive species like Tsuga canadensis for future work. Results here indicate that Liriodendron tulipifera is nearly an ideal replacement for Tsuga canadensis, especially given the recent discovery of it living >500 years (Pederson 2010) (see supplemental material). Our findings indicate Betula lenta, Carya glabra and Quercus rubra as useful "novel" species for paleohydroclimatic research (supplemental material). In fact, comparison of PDSI reconstruction using only "Traditional" versus "Novel" species shows little difference in the performance of the two groupings (Table 2). The differences that do occur in the resulting reconstruction do not seem to consistently favor one grouping of species versus the other (supplemental Fig. S7). While these "novel" species generally do not live as long as Tsuga canadensis (Eastern OLDLIST 2012), the nested reconstruction approach makes shorter chronologies useful for paleoclimatic research. Continued exploration of species in the diverse eastern North American forest for maximum ages and climatic sensitivity should help future dendroclimatological research as species are lost, either functionally or permanently.

\section{e. Implications for NYC water supply}

Current supply levels for NYC are anomalous within the context of the last 500 years. NYC currently enjoys a water supply surplus and rotates its water demand among three watershed systems- the Croton, Catskill, and Delaware watersheds-from year to year (NYC Department of Environmental Protection 2010). It might appear thus that NYC possesses a surplus of water use rights that might be better allocated to downstream users of the basin in Delaware, New Jersey, and Pennsylvania. However, we argue that a reallocation of NYC's water rights may well put metropolitan water supply at risk, should the current trend toward strong pluvial conditions come to an end. In fact, forecasts of future precipitation indicate continued wetting during winter, but drying during the summer (Hayhoe et al. 2007). The gains in water conservation and efficiency made by NYC during a time of comparative abundance are admirable [from a per capita consumption peak of $788.5 \mathrm{~L} \mathrm{day}^{-1}$ (LPD) in 1988 to a low in 2009 of 476.2 LPD, a reduction of $40 \%$ ] (NYC Department of Environmental Protection 2010), and may turn out to have been prescient if and when NYC's "water boom" comes to an end. We suggest the value in framing NYC's current condition as a "water boom" rather than a "water surplus," and note the insight from natural resource economics that benefits accrued from resource booms are better saved than consumed (because reducing consumption rates is much more painful and difficult than reducing rates of saving) (Collier 2010). To its credit NYC has already done much to avoid a consumption boom in water resources, and we hope that the context provided in this study will demonstrate the importance of "saving" the current abundance of water resources-perhaps through facilitating watershed restoration and improving the provision of ecosystem services by the Delaware and Catskill watersheds, or through short-term leases of NYC's current surplus with the revenues invested in water infrastructure-while the boom lasts. Ephemeral though it may turn out to be, the capacity for NYC to act as a buffer within a collaborative regional network of water supply and demand (and collect revenue in the process) is an opportunity not to be missed.

\section{Summary}

Here we present a well-replicated reconstruction of hydroclimate for the NYC region from 1531 to 2011. The new reconstruction reveals an upward trend toward more pluvial conditions since ca. 1800 for a significant portion of the northeastern United States, a trend that is manifest over much of temperate eastern North America. This trend is currently punctuated by an unusual, 43-yr pluvial and supports instrumental data indicating that the last two decades are unusual in nature. With greater chronology replication in the sixteenth and seventeenth centuries than previous regional reconstructions, the new record reveals a high frequency of droughts during the sixteenth and seventeenth centuries that are similar in intensity to the 1960s drought, the drought of 
record in the instrumental data. We now have evidence that the well-known sixteenth century megadrought likely occurred over much of the northeastern United States. Here, the sixteenth century is characterized by an unprecedented 23-yr drought that follows in short succession two other significant drought events. Perhaps just as important, the seventeenth century is characterized by six severe drought events after 1633. In a 500-yr context, the twentieth century and the sustained and repeated pluvial events over the last 43 years mask the real likelihood for severe and significant drought in the greater NYC region. Water supply systems for millions of people need to be viewed as vulnerable to severe and potentially frequent drought. With this perspective, we suggest that the current conditions within the NYC watershed be seen as a water boom, not surplus. During booms it might be best to focus management on saving the current abundance of water resources.

Acknowledgments. This work was partially supported by a fellowship provided to NP by the U.S. Department of Energy Global Change Education Program. Critical feedback by C. Leland, D. Martin, and C. Ummenhofer improved earlier versions of this manuscript.

\section{REFERENCES}

Akkemik, U., N. Dağdeviren, and A. Aras, 2005: A preliminary reconstruction (A.D. 1635-2000) of spring precipitation using oak tree rings in the western Black Sea region of Turkey. Int. J. Biometeor., 49, 297-302.

Archambault, H. M., L. F. Bosart, D. Keyser, and A. R. Aiyyer, 2008: Influence of large-scale flow regimes on cool-season precipitation in the Northeastern United States. Mon. Wea. Rev., 136, 2945-2963.

Argyilan, E. P., S. L. Forman, J. W. Johnston, and D. A. Wilcox, 2005: Optically stimulated luminescence dating of late Holocene raised strandplain sequences adjacent to Lakes Michigan and Superior, Upper Peninsula, Michigan, USA. Quat. Res., 63, 122-135.

Bégin, Y., and S. Peyette, 1988: Dendroecological evidence of lakelevel changes during the last three centuries in subarctic Quebec. Quat. Res., 30, 210-220.

Biondi, F., T. J. Kozubowski, and A. K. Panorska, 2002: Stochastic modeling of regime shifts. Climate Res., 23, 23-30.

,-- , and -2005 : A new model for quantifying climate episodes. Int. J. Climatol., 25, 1253-1264.

Bonneau, L. R., K. S. Shields, and D. L. Civco, 1999: A technique to identify changes in hemlock forest health over space and time using satellite image data. Biol. Invasions, 1, 269-279.

Brown, P. J., R. S. Bradley, and F. T. Keimig, 2010: Changes in extreme climate indices for the northeastern United States, 1870-2005. J. Climate, 23, 6555-6572.

Buckley, B. M., R. J. S. Wilson, P. E. Kelly, D. W. Larson, and E. R. Cook, 2004: Inferred summer precipitation for southern Ontario back to A.D. 610, as reconstructed from ring widths of Thuja occidentalis. Can. J. For. Res., 34, 25412553.
- and Coauthors, 2010: Climate as a contributing factor in the demise of Angkor, Cambodia. Proc. Natl. Acad. Sci. USA, 107, 6748-6752.

Budikova, D., 2008: Effect of the Arctic Oscillation on precipitation in the eastern USA during ENSO winters. Climate Res., 37, 3-16.

Büntgen, U., and W. Tegel, 2011: European tree-ring data and the Medieval Climate Anomaly. PAGES News, Vol. 19, No. 1, PAGES International Project Office, Bern, Switzerland, 14-15. , and Coauthors, 2011: 2500 years of European climate variability and human susceptibility. Science, 331, 578-582.

Burns, D., J. Klaus, and M. Mchale, 2007: Recent climate trends and implications for water resources in the Catskill Mountain region, New York, USA. J. Hydrol., 336, 155-170.

Cleaveland, M. K., D. W. Stahle, M. D. Therrell, J. VillanuevaDiaz, and B. T. Burns, 2003: Tree-ring reconstructed winter precipitation and tropical teleconnections in Durango, mexico. Climatic Change, 59, 369-388.

Collier, P., 2010: The Plundered Planet: Why We Must, and How We Can, Manage Nature for Global Prosperity. Oxford University Press, $288 \mathrm{pp}$.

Cook, B. I., E. R. Cook, K. J. Anchukaitis, R. Seager, and R. L. Miller, 2010: Forced and unforced variability of twentieth century North American droughts and pluvials. Climate Dyn., 37, 1097-1110.

Cook, E. R., 1982: Tree-ring data networks: Comment. Climate from Tree Rings, 1st ed. M. K. Hughes et al., Eds., Cambridge University Press, 6-7.

_ 1985: A time series analysis approach to tree ring standardization. Ph.D. dissertation, The University of Arizona, $171 \mathrm{pp}$.

_- and G. Jacoby, 1977: Tree-ring-drought relationships in the Hudson Valley, New York. Science, 198, 399-401.

, and K. Peters, 1981: The smoothing spline: A new approach to standardizing forest interior tree-ring width series for dendroclimatic studies. Tree-Ring Bull., 41, 45-53.

— , and G. C. Jacoby, 1983: Potomac River streamflow since 1730 as reconstructed by tree rings. J. Climate Appl. Meteor., 22, $1659-1672$.

_ , and L. A. Kariukstis, Eds., 1990: Methods of Dendrochronology: Applications in the Environmental Sciences. Kluwer Academic, $408 \mathrm{pp}$.

- and K. Peters, 1997: Calculating unbiased tree-ring indices for the study of climatic and environmental change. Holocene, 7, 361-370.

, and P. J. Krusic, cited 2004: The North American Drought Atlas. Lamont-Doherty Earth Observatory and the National Science Foundation. [Available online at http://iridl.ldeo. columbia.edu/SOURCES/.LDEO/.TRL/.NADA2004/.pdsi-atlas. html.]

, and N. Pederson, 2011: Uncertainty, emergence, and statistics in dendrochronology. Dendroclimatology, Developments in Paleoenvironmental Research, M. K. Hughes, T.W. Swetnam, and H. F. Diaz, Eds., Vol. 11, Springer, 77-112.

_, K. R. Briffa, and P. D. Jones, 1994: Spatial regression methods in dendroclimatology: A review and comparison of two techniques. Int. J. Climatol., 14, 379-402.

D. M. Meko, D. W. Stahle, and M. K. Cleaveland, 1999: Drought reconstructions for the continental United States. J. Climate, 12, 1145-1162.

_ , R. D. D'Arrigo, and M. E. Mann, 2002: A well-verified, multiproxy reconstruction of the winter North Atlantic Oscillation index since AD 1400. J. Climate, 15, 1754-1764. 
— P. J. Krusic, and P. D. Jones, 2003: Dendroclimatic signals in long tree-ring chronologies from the Himalayas of Nepal. Int. J. Climatol., 23, 707-732.

—, C. A. Woodhouse, C. M. Eakin, D. M. Meko, and D. W. Stahle, 2004: Long-term aridity changes in the western United States. Science, 306, 1015-1018.

— reconstructions, version 2a. [Available online at http://www. ncdc.noaa.gov/paleo/pdsi.html.]

— Seager, R. R. J. Heim, R. S. Vose, C. Herweijer, and C. A. Woodhouse, 2010: Megadroughts in North America: Placing IPCC projections of hydroclimatic change in a long-term palaeoclimate context. J. Quat. Sci., 25, 48-61.

—_ P. J. Krusic, R. H. Holmes, and K. Peters, cited 2011: Program ARSTAN Ver.41d 10.5. [Available online at http://www.ldeo.columbia.edu/tree-ring-laboratory/resources/ software.]

Davi, N. K., G. C. Jacoby, A. E. Curtis, and N. Baatarbileg, 2006: Extension of drought records for central Asia using tree rings: West-central Mongolia. J. Climate, 19, 288-299.

$\longrightarrow,-$, R. D. D'Arrigo, N. Baatarbileg, L. Jinbao, and A. E. Curtis, 2009: A tree-ring-based drought index reconstruction for far-western Mongolia: 1565-2004. Int. J. Climatol., 29, $1508-1514$

Davis, R. E., B. P. Hayden, D. A. Gay, W. L. Phillips, and G. V. Jones, 1997: The North Atlantic subtropical anticyclone. J. Climate, 10, 728-744.

Devineni, N., U. Lall, N. Pederson, and E. R. Cook, 2013: A treering-based reconstruction of Delaware River basin streamflow using hierarchical Bayesian regression. J. Climate, in press.

Easterling, D. R., G. A. Meehl, C. Parmesan, S. A. Changnon, T. R. Karl, and L. O. Mearns, 2000: Climate extremes: Observations, modeling, and impacts. Science, 289, 2068-2074.

Eastern OLDLIST, cited 2012: Eastern OLDLIST: A database of maximum tree ages for eastern North America. [Available online at http://www.ldeo.columbia.edu/ adk/oldlisteast/.]

Fang, K., X. Gou, F. Chen, F. Zhang, Y. Li, and J. Peng, 2010: Comparisons of drought variability between central High Asia and monsoonal Asia: Inferred from tree rings. Front. Earth Sci. Chin., 4, 277-288.

Frank, D., and J. Esper, 2005: Characterization and climate response patterns of a high-elevation, multi-species tree-ring network in the European Alps. Dendrochronologia, 22, 107-121.

Friedman, J. H., 1984: A Variable Span Smoother. Stanford University, $30 \mathrm{pp}$.

Fritts, H. C., 1976: Tree Rings and Climate. Academic Press, 567 pp.

Fye, F. K., D. W. Stahle, and E. R. Cook, 2003: Paleoclimatic analogs to twentieth-century moisture regimes across the United States. Bull. Amer. Meteor. Soc., 84, 901-909.

García-Suárez, A. M., C. J. Butler, and M. G. L. Baillie, 2009: Climate signal in tree-ring chronologies in a temperate climate: A multi-species approach. Dendrochronologia, 27, 183-198.

Gong, G., L. Wang, and U. Lall, 2011: Climatic precursors of autumn streamflow in the northeast United States. Int. J. Climatol., 31, 1773-1784.

Gou, X., Y. Deng, F. Chen, M. Yang, K. Fang, L. Gao, T. Yang, and F. Zhang, 2010: Tree ring based streamflow reconstruction for the Upper Yellow River over the past 1234 years. Chin. Sci. Bull., 55, 4179-4186.

Gray, S. T., J. J. Lukas, and C. A. Woodhouse, 2011: Millenniallength records of streamflow from three major upper Colorado River tributaries. J. Amer. Water Resour. Assoc., 47, 702-712.
Groisman, P. Ya., R. W. Knight, T. R. Karl, D. R. Easterling, B. Sun, and J. H. Lawrimore, 2004: Contemporary changes of the hydrological cycle over the contiguous United States: Trends derived from in situ observations. J. Hydrometeor., 5, 64-85.

Hardt, B., H. D. Rowe, G. S. Springer, H. Cheng, and R. L. Edwards, 2010: The seasonality of east central North American precipitation based on three coeval Holocene speleothems from southern West Virginia. Earth Planet. Sci. Lett., 295, 342348.

Hayhoe, K., and Coauthors, 2007: Past and future changes in climate and hydrological indicators in the US Northeast. Climate Dyn., 28, 381-407.

Hodgkins, G. A., and R. W. Dudley, 2011: Historical summer base flow and stormflow trends for New England rivers. Water Resour. Res., 47, 1-16.

Horton, R., C. Rosenzweig, V. Gornitz, D. Bader, and M. O'Grady, 2009: Climate Risk Information. New York City Panel on Climate Change, $67 \mathrm{pp}$.

_ , V. Gornitz, D. A. Bader, A. C. Ruane, R. Goldberg, and C. Rosenzweig, 2011: Climate hazard assessment for stakeholder adaptation planning in New York City. J. Appl. Meteor. Climatol., 50, 2247-2266.

Ireland, A. W., and R. K. Booth, 2011: Hydroclimatic variability drives episodic expansion of a floating peat mat in a North American kettlehole basin. Ecology, 92, 11-18.

Joyce, T. M., Y.-O. Kwon, and L. Yu, 2009: On the relationship between synoptic wintertime atmospheric variability and path shifts in the Gulf Stream and the Kuroshio Extension. J. Climate, 22, 3177-3192.

Kagawa, A., A. Sugimoto, and T. C. Maximov, 2006: $13 \mathrm{CO}_{2}$ pulselabelling of photoassimilates reveals carbon allocation within and between tree rings. Plant Cell Environ., 29, 1571-1584.

Karl, T. R., and R. W. Knight, 1998: Secular trends of precipitation amount, frequency, and intensity in the United States. Bull. Amer. Meteor. Soc., 79, 231-241.

_ J. M. Melillo, and T. C. Peterson, Eds., 2009: Global Climate Changes in the United States. Cambridge University Press, 192 pp.

Knight, T. A., D. M. Meko, and C. H. Baisan, 2010: A bimillenniallength tree-ring reconstruction of precipitation for the Tavaputs Plateau, Northeastern Utah. Quat. Res., 73, 107-117.

Köse, N., Ü. Akkemik, H. N. Dalfes, and M. S. Özeren, 2011: Treering reconstructions of May-June precipitation for western Anatolia. Quat. Res., 75, 438-450.

Kunkel, K. E., K. Andsager, and D. R. Easterling, 1999: Long-term trends in extreme precipitation events over the conterminous United States and Canada. J. Climate, 12, 2515-2527.

Li, J., X. Gou, E. R. Cook, and F. Chen, 2006: Tree-ring based drought reconstruction for the central Tien Shan area in northwest China. Geophys. Res. Lett., 33, L07715, doi:10.1029/ 2006GL025803.

Lichter, J., 1997: AMS radiocarbon dating of Lake Michigan beach-ridge and dune development. Quat. Res., 48, 137-140.

Loope, W. L., and A. F. Arbogast, 2000: Dominance of an $~ 150$ year cycle of sand-supply change in late Holocene dunebuilding along the eastern shore of Lake Michigan. Quat. Res., 54, 414-422.

Lyon, B., N. Christie-Blick, and Y. Gluzberg, 2005: Water shortages, development, and drought in Rockland County, New York. J. Amer. Water Resour. Assoc., 41, 1457-1469.

Maxwell, R. S., A. E. Hessl, E. R. Cook, and N. Pederson, 2011: A multispecies tree ring reconstruction of Potomac River streamflow (950-2001). Water Resour. Res., 47, 1-12. 
McEwan, R. W., J. M. Dyer, and N. Pederson, 2011: Multiple interacting ecosystem drivers: Toward an encompassing hypothesis of oak forest dynamics across eastern North America. Ecography, 34, 244-256.

Meko, D., 1997: Dendroclimatic reconstruction with time varying predictor subsets of tree indices. J. Climate, 10, 687-696.

— construction to water resources management. Dendroclimatology, Developments in Paleoenvironmental Research, M. K. Hughes, T. W. Swetnam, and H. F. Diaz, Eds., Vol. 11, Springer Netherlands, 231-261.

Melvin, T., and K. Briffa, 2008: A "signal-free" approach to dendroclimatic standardisation. Dendrochronologia, 26, $71-86$.

Min, S.-K., X. Zhang, F. W. Zwiers, and G. C. Hegerl, 2011: Human contribution to more-intense precipitation extremes. Nature, 470, 378-381.

Namias, J., 1966: Nature and possible causes of the northeastern United States drought during 1962-65. Mon. Wea. Rev., 94, 543-554.

Narisma, G. T., J. A. Foley, R. Licker, and N. Ramankutty, 2007: Abrupt changes in rainfall during the twentieth century. Geophys. Res. Lett., 34, L06710, doi:10.1029/2006GL028628.

Nichols, J. E., 2010: Reconstructing Holocene hydroclimate in eastern North America from ombrotrophic peatland sediments. Ph.D. dissertation, Brown University, 207 pp.

Nielsen, E., 1998: Lake Winnipeg coastal submergence over the last three centuries. J. Paleolimnol., 19, 335-342.

NYC Department of Environmental Protection, cited 2010: New York City 2010 drinking water supply and quality report. [Available online at http://www.nyc.gov/html/dep/html/ drinking_water/wsstate.shtml.]

_- cited 2011: Drought and water consumption. [Available online at http://www.nyc.gov/html/dep/html/drinking_water/ droughthist.shtml.]

NYC Department of Planning, cited 2006: New York City population projections by age/sex and borough. [Available online at www.nyc.gov/html/dcp/pdf/census/projections_briefing booklet.pdf.]

Orwig, D. A., and D. R. Foster, 1998: Forest response to the introduced hemlock woolly adelgid in southern New England, USA. J. Torrey Bot. Soc., 125, 60-73.

—, R. C. Cobb, A. W. D'Amato, M. L. Kizlinski, and D. R. Foster, 2008: Multi-year ecosystem response to hemlock woolly adelgid infestation in southern New England forests. Can. J. For. Res., 38, 834-843.

Pederson, D., D. Peteet, D. Kurdyla, and T. Guilderson, 2005: Medieval warming, little ice age, and European impact on the environment during the last millennium in the lower Hudson Valley, New York, USA. Quat. Res., 63, 238-249.

Pederson, N., 2005: Climatic Sensitivity and Growth of Southern Temperate Trees in the Eastern US: Implications for the Carbon Cycle. Columbia University, 186 pp.

_ 2010: External characteristics of old trees in the eastern deciduous forest. Nat. Areas J., 30, 396-407.

—, G. C. Jacoby, R. D. D'Arrigo, E. R. Cook, B. M. Buckley, C. Dugarjav, and R. Mijiddorj, 2001: Hydrometeorological reconstructions for northeastern Mongolia derived from tree rings: 1651-1995. J. Climate, 14, 872-881.

, E. R. Cook, G. C. Jacoby, D. M. Peteet, and K. L. Griffin, 2004: The influence of winter temperatures on the annual radial growth of six northern range margin tree species. Dendrochronologia, 22, 7-29.
— , and Coauthors, 2012a: Insight into the American Southeast's drought future from its reconstructed drought past. Environ. Res. Lett., 7, 014034, doi:10.1088/1748-9326/7/1/014034.

—, K. Tackett, R. W. McEwan, S. Clark, A. Cooper, G. Brosi, R. Eaton, and R. D. Stockwell, 2012b: Long-term drought sensitivity of trees in second-growth forests in a humid region. Can. J. For. Res., 42, 1837-1850.

Rodionov, S. N., 2004: A sequential algorithm for testing climate regime shifts. Geophys. Res. Lett., 31, L09204, doi:10.1029/ 2004GL019448.

Seager, R., N. Pederson, Y. Kushnir, J. Nakamura, and S. Jurburg, 2012: The 1960s drought and the subsequent shift to a wetter climate in the Catskill Mountains region of the New York City watershed. J. Climate, 25, 6721-6742.

Sheppard, P. R., P. E. Tarasov, L. J. Graumlich, K.-U. Heussner, M. Wagner, H. Sterle, and L. G. Thompson, 2004: Annual precipitation since 515 B.C. reconstructed from living and fossil juniper growth of northeastern Qinghai Province, China. Climate Dyn., 23, 869-881.

Shuman, B., A. K. Henderson, C. Plank, I. Stefanova, and S. S. Ziegler, 2009: Woodland-to-forest transition during prolonged drought in Minnesota after ca. A.D. 1300. Ecology, 90, 27922807.

Spierre, S. G., and C. Wake, 2010: Trends in Extreme Precipitation Events for the Northeastern United States 1948-2007. Durham, $17 \mathrm{pp}$.

Stahle, D. W., and M. K. Cleaveland, 1992: Reconstruction and analysis of spring rainfall over the southeastern United States for the past 1000 years. Bull. Amer. Meteor. Soc., 73, 19471961.

_, and _ 1994: Tree-ring reconstructed rainfall over the southeastern USA during the Medieval Warm Period and Little Ice Age. Climatic Change, 26, 199-212.

_ - , and J. Hehr, 1988: North Carolina climate changes reconstructed from tree rings: AD 372 to 1985. Science, 240, $1517-1519$

— , and Coauthors, 2000: Tree-ring data document 16th century megadrought over North America. Eos, Trans. Amer. Geophys. Union, 81, 12, doi:10.1029/00EO00076.

Stockton, C., and G. Jacoby, 1976: Long-term surface-water supply and streamflow trends in the Upper Colorado River basin based on tree-ring analyses. Lake Powell Res. Proj. Bull., 18, $1-70$.

Touchan, R., Ü. Akkemik, M. K. Hughes, and N. Erkan, 2007: May-June precipitation reconstruction of southwestern Anatolia, Turkey during the last 900 years from tree rings. Quat. Res., 68, 196-202.

Treydte, K. S., G. H. Schleser, G. Helle, D. C. Frank, M. Winiger, G. H. Haug, and J. Esper, 2006: The twentieth-century was the wettest period in northern Pakistan over the past millennium. Nature, 440, 1179-1182.

Trumbore, S., J. Gaudinski, P. Hanson, and J. Southon, 2002: Quantifying ecosystem-atmosphere carbon exchange with a $14 \mathrm{C}$ label. Eos, Trans. Amer. Geophys. Union, 83, 24, doi:10.1029/ 2002 EO000187.

Wigley, T., K. Briffa, and P. Jones, 1984: On the average value of correlated time series, with applications in dendroclimatology and hydrometeorology. J. Climate Appl. Meteor., 23, 201-213.

Wilson, R. J. S., B. H. Luckman, and J. Esper, 2005: A 500 year dendroclimatic reconstruction of spring-summer precipitation from the lower Bavarian Forest region, Germany. Int. J. Climatol., 25, 611-630. 
Wolin, J. A., 1996: Late Holocene lake-level and lake development signals in Lower Herring Lake, Michigan. J. Paleolimnol., 15, $19-45$.

Woodhouse, C. A., and J. Lukas, 2006: Drought, tree rings and water management in Colorado. Can. Water Resour., 31, 114.

K. E. Kunkel, D. R. Easterling, and E. R. Cook, 2005: The twentieth-century pluvial in the western United States. Geophys. Res. Lett., 32, L07701, doi:10.1029/2005GL022413.

, D. M. Meko, G. M. MacDonald, D. W. Stahle, and E. R. Cook, 2010: A 1200-year perspective of 21st century drought in southwestern North America. Proc. Natl. Acad. Sci. USA, 107, 21 283-21 288.

Yin, Z.-Y., X. Shao, N. Qin, and E. Liang, 2008: Reconstruction of a 1436-year soil moisture and vegetation water use history based on tree-ring widths from Qilian junipers in northeastern Qaidam Basin, northwestern China. Int. J. Climatol., 28, 37-53.

Zhang, Y., Q. Tian, X. Gou, F. Chen, S. W. Leavitt, and Y. Wang, 2011: Annual precipitation reconstruction since A.D. 775 based on tree rings from the Qilian Mountains, northwestern China. Int. J. Climatol., 31, 371-381. 


\section{Supplemental Tables}

Table S1 - Chronologies used and their statistics for NYC Watershed drought reconstruction.

\begin{tabular}{|c|c|c|c|c|c|c|c|c|}
\hline Site & Spp & CRN Span & $\begin{array}{l}\text { No. } \\
\text { Ser }\end{array}$ & $\begin{array}{c}\text { EPS } \\
\text { (Tree) }\end{array}$ & $\begin{array}{c}\text { EPS } \\
>0.80\end{array}$ & $\begin{array}{l}\text { Yr EPS } \\
>0.80^{c}\end{array}$ & $\begin{array}{c}\text { Med. Seg. } \\
\text { (yrs) }\end{array}$ & Comments \\
\hline & & & . & $\mathbf{a}$ & $\mathrm{b}$ & & & \\
\hline Albany-Middleburgh, NY & QUlue & $\begin{array}{l}\text { 1507- } \\
2002\end{array}$ & 63 & 0.944 & 1581 & - & 168 & $\begin{array}{l}\text { Live trees = Quercus montana; } \\
\text { dead trees = Q. subgenus } \\
\text { Leucobalanus species from } \\
\text { Albany, NY region }\end{array}$ \\
\hline Greenbrook Sanctuary, & CAGL & $1818-$ & 18 & 0.883 & 1847 & - & 105 & \\
\hline NJ & & 2000 & & & & & & \\
\hline Greenbrook Sanctuary, & LITU & $1750-$ & 27 & 0.918 & 1800 & - & 152 & \\
\hline NJ & & 2000 & & & & & & \\
\hline Goose Egg Forest, NY & QUAL & $\begin{array}{l}1666- \\
2002\end{array}$ & 35 & 0.963 & 1743 & - & 186 & \\
\hline Goose Egg Forest, NY & QUMO & $1666-$ & 31 & 0.958 & 1746 & - & 163 & \\
\hline
\end{tabular}


2002

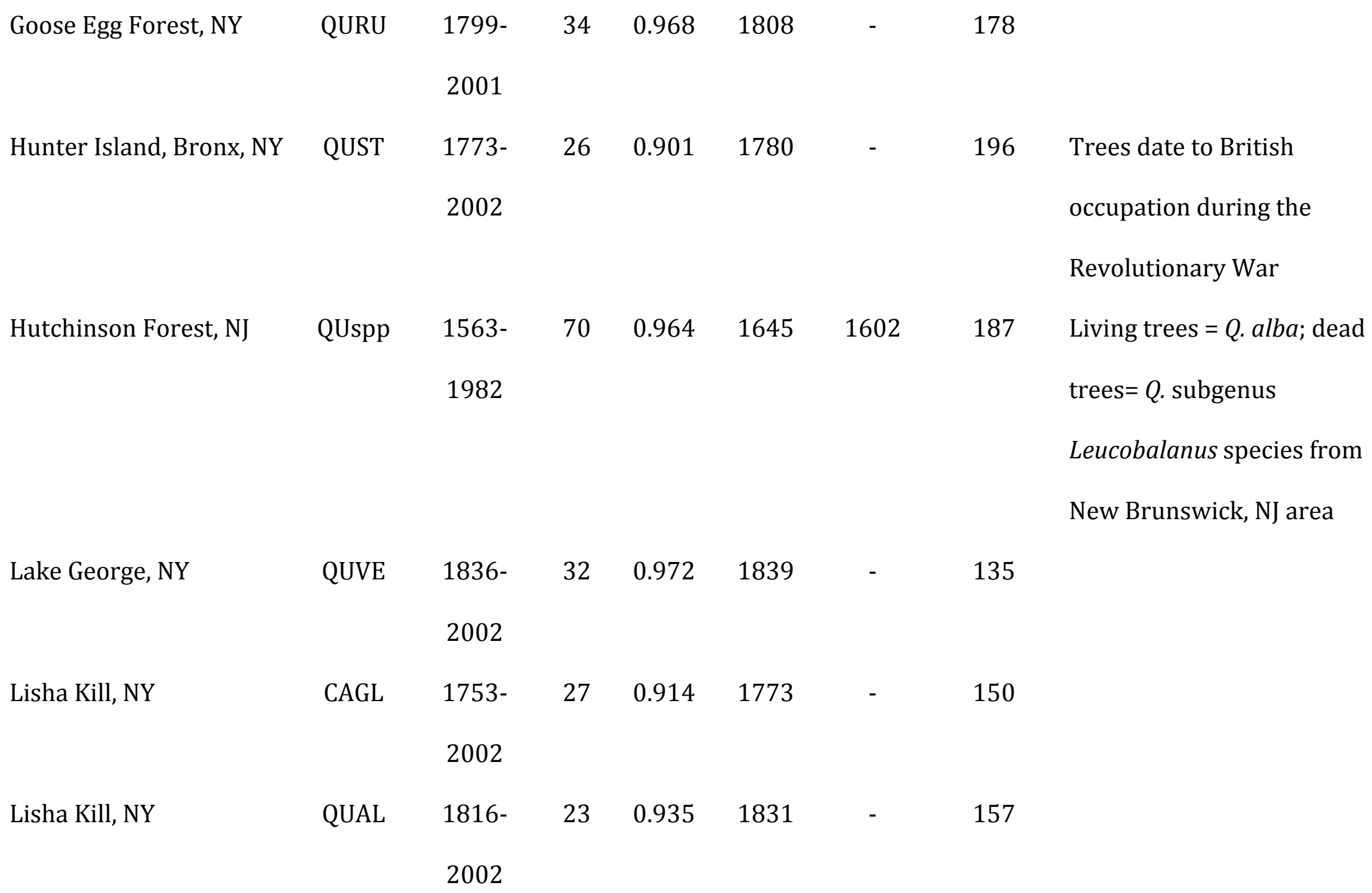




\begin{tabular}{|c|c|c|c|c|c|c|c|c|}
\hline Middleburgh, NY & JUVI & $\begin{array}{l}1449- \\
2004\end{array}$ & 26 & 0.860 & 1525 & 1515 & 152 & Live \& dead wood \\
\hline Mohonk, NY & BELE & $\begin{array}{l}1614- \\
2002\end{array}$ & 29 & 0.950 & 1834 & 1817 & 129 & Collected in $1974 \& 2002$ \\
\hline Mohonk, NY & CAGL & $\begin{array}{l}1740- \\
2002\end{array}$ & 30 & 0.940 & 1850 & 1847 & 152 & \\
\hline Mohonk, NY & PIRI & $\begin{array}{l}\text { 1618- } \\
1996\end{array}$ & 45 & 0.967 & 1670 & - & 210 & Approximate location \\
\hline Mohonk, NY & QUlue & $\begin{array}{l}1449- \\
2002\end{array}$ & 157 & 0.981 & 1550 & 1531 & 158 & $\begin{array}{l}\text { Living portion is Quercus } \\
\text { montana; the historical } \\
\text { timbers portion is } Q \text {. } \\
\text { subgenus Leucobalanus } \\
\text { species from timbers in the } \\
\text { New Paltz, NY area }\end{array}$ \\
\hline Mohonk, NY & QUVE & $\begin{array}{l}1793- \\
2002\end{array}$ & 27 & 0.959 & 1795 & - & 162 & \\
\hline
\end{tabular}




\begin{tabular}{|c|c|c|c|c|c|c|c|c|}
\hline \multirow[t]{2}{*}{ Mohonk, NY } & TSCA & $1626-$ & 43 & 0.973 & 1705 & 1662 & 243 & Humpty Dumpty talus \\
\hline & & 2002 & & & & & & \\
\hline \multirow[t]{2}{*}{ Mohonk, NY } & TSCA & $1658-$ & 39 & 0.963 & 1735 & 1691 & 211 & Rock Rift Rd \\
\hline & & 2004 & & & & & & \\
\hline \multirow[t]{2}{*}{ Mohonk, NY } & TSCA & $1579-$ & 21 & 0.964 & 1604 & - & 252 & Spruce Glen \\
\hline & & 2000 & & & & & & \\
\hline \multirow[t]{2}{*}{ Montgomery Place, NY } & LITU & $1754-$ & 20 & 0.905 & 1885 & 1852 & 113 & \\
\hline & & 2002 & & & & & & \\
\hline \multirow[t]{2}{*}{ Montgomery Place, NY } & QUMO & $1727-$ & 33 & 0.941 & 1830 & 1805 & 179 & \\
\hline & & 2002 & & & & & & \\
\hline \multirow[t]{2}{*}{ Montgomery Place, NY } & QURU & $1787-$ & 28 & 0.928 & 1870 & 1839 & 130 & \\
\hline & & 2002 & & & & & & \\
\hline \multirow[t]{3}{*}{ Pack Forest, NY } & TSCA & $1453-$ & 89 & 0.970 & 1557 & - & 208 & Orig. Pack For. TSCA, western \\
\hline & & 2003 & & & & & & MA update \& historical \\
\hline & & & & & & & & timbers \\
\hline Prospect Mountain, NY & BELE & $1820-$ & 24 & 0.915 & 1831 & - & 121 & \\
\hline
\end{tabular}


2001

\begin{tabular}{|c|c|c|c|c|c|c|c|c|}
\hline Prospect Mountain, NY & CAOV & $\begin{array}{l}1775- \\
2001\end{array}$ & 29 & 0.939 & 1830 & - & 165 & \\
\hline Prospect Mountain, NY & QUAL & $\begin{array}{l}1659- \\
2001\end{array}$ & 32 & 0.966 & 1760 & - & 191 & \\
\hline Prospect Mountain, NY & QURU & $\begin{array}{l}1816- \\
2001\end{array}$ & 28 & 0.934 & 1834 & - & 127 & \\
\hline Schenectady, NY & QUVE & $\begin{array}{l}1802- \\
2001\end{array}$ & 24 & 0.927 & 1802 & - & 167 & \\
\hline Schunnemunk Mtn, NY & QUAL & $\begin{array}{l}1648- \\
2001\end{array}$ & 46 & 0.928 & 1700 & - & 244 & Collected in 1983 \& 2001 \\
\hline Uttertown, NJ & LITU & $\begin{array}{l}1732- \\
2003\end{array}$ & 28 & 0.961 & 1757 & - & 147 & \\
\hline Uttertown, NJ & QUspp & $\begin{array}{l}1491- \\
2002\end{array}$ & 65 & 0.956 & 1516 & - & 206 & $\begin{array}{l}\text { Live trees = } Q \text { montana; } \\
\text { historical timbers }=Q\end{array}$ \\
\hline
\end{tabular}


2001

\section{Median}

$\mathbf{a}=$ between tree EPS; $^{\mathbf{b}}=$ segment where between-tree EPS $>0.80 ;^{\mathbf{c}}=$ year when between-tree EPS $>0.80$ if earlier than ${ }^{b}$ 
Table S2 - Calibration-validation statistics for the NYC Watershed reconstruction. RE = reduction of error statistic. CE = coefficient of efficiency. See manuscript for statistic descriptions.

\begin{tabular}{|c|c|c|c|c|c|c|c|c|c|c|c|c|c|c|}
\hline \multirow[t]{2}{*}{ Nest } & \multirow{2}{*}{$\begin{array}{l}\text { No. } \\
\text { Crns }\end{array}$} & $\mathbf{r}^{2}$ & \multicolumn{4}{|c|}{ Pearson $r$} & \multicolumn{4}{|c|}{ RE } & \multicolumn{4}{|c|}{ CE } \\
\hline & & & \multicolumn{12}{|c|}{-- Backwards Nest -- } \\
\hline & & 1895- & \multicolumn{2}{|c|}{$1895-' 24$} & \multicolumn{2}{|c|}{$1925-' 81$} & \multicolumn{2}{|c|}{$1895-' 24$} & \multicolumn{2}{|c|}{$1925-` 81$} & \multicolumn{2}{|c|}{$1895-' 24$} & \multicolumn{2}{|c|}{$1925-{ }^{\prime} 81$} \\
\hline & & 1981 & Calib. & Veri. & Calib. & Veri. & Calib. & Veri. & Calib. & Veri. & Calib. & Veri. & Calib. & Veri. \\
\hline 1515 & 2 & 26.9 & & & & & & & & & & & & \\
\hline 1531 & 3 & 44.1 & 0.754 & 0.527 & 0.676 & 0.504 & 0.568 & 0.241 & 0.458 & 0.241 & 0.568 & 0.207 & 0.458 & 0.230 \\
\hline 1557 & 4 & 45.7 & 0.796 & 0.449 & 0.666 & 0.476 & 0.634 & 0.168 & 0.444 & 0.200 & 0.634 & 0.131 & 0.444 & 0.188 \\
\hline 1581 & 5 & 48.2 & 0.757 & 0.550 & 0.712 & 0.515 & 0.573 & 0.294 & 0.507 & 0.220 & 0.573 & 0.263 & 0.507 & 0.209 \\
\hline 1602 & 6 & 49.6 & 0.751 & 0.651 & 0.735 & 0.676 & 0.563 & 0.425 & 0.541 & 0.329 & 0.563 & 0.419 & 0.541 & 0.317 \\
\hline 1662 & 7 & 53.2 & 0.732 & 0.733 & 0.768 & 0.678 & 0.536 & 0.481 & 0.590 & 0.321 & 0.536 & 0.475 & 0.590 & 0.309 \\
\hline
\end{tabular}




\begin{tabular}{|c|c|c|c|c|c|c|c|c|c|c|c|c|c|c|}
\hline 1670 & 8 & 55.2 & 0.787 & 0.735 & 0.777 & 0.747 & 0.619 & 0.481 & 0.604 & 0.467 & 0.619 & 0.475 & 0.604 & 0.458 \\
\hline 1691 & 9 & 57.0 & 0.791 & 0.742 & 0.775 & 0.744 & 0.625 & 0.492 & 0.641 & 0.471 & 0.625 & 0.487 & 0.641 & 0.462 \\
\hline 1700 & 10 & 57.5 & 0.781 & 0.747 & 0.744 & 0.722 & 0.610 & 0.495 & 0.599 & 0.441 & 0.610 & 0.490 & 0.599 & 0.431 \\
\hline 1744 & 12 & 58.1 & 0.776 & 0.754 & 0.783 & 0.714 & 0.602 & 0.490 & 0.612 & 0.327 & 0.602 & 0.484 & 0.612 & 0.315 \\
\hline 1758 & 14 & 58.4 & 0.773 & 0.757 & 0.787 & 0.702 & 0.598 & 0.469 & 0.620 & 0.315 & 0.598 & 0.463 & 0.620 & 0.303 \\
\hline 1773 & 15 & 59.1 & 0.771 & 0.775 & 0.789 & 0.690 & 0.595 & 0.483 & 0.623 & 0.274 & 0.595 & 0.478 & 0.623 & 0.261 \\
\hline 1780 & 16 & 58.8 & 0.771 & 0.764 & 0.799 & 0.700 & 0.595 & 0.452 & 0.639 & 0.251 & 0.595 & 0.447 & 0.639 & 0.238 \\
\hline 1795 & 17 & 58.5 & 0.771 & 0.764 & 0.799 & 0.688 & 0.595 & 0.452 & 0.638 & 0.253 & 0.595 & 0.447 & 0.638 & 0.240 \\
\hline 1802 & 19 & 60.3 & 0.789 & 0.752 & 0.810 & 0.682 & 0.623 & 0.454 & 0.657 & 0.269 & 0.623 & 0.448 & 0.657 & 0.257 \\
\hline 1805 & 22 & 64.0 & 0.788 & 0.771 & 0.822 & 0.710 & 0.621 & 0.479 & 0.685 & 0.286 & 0.621 & 0.473 & 0.685 & 0.274 \\
\hline 1817 & 23 & 63.2 & 0.794 & 0.773 & 0.822 & 0.719 & 0.630 & 0.487 & 0.676 & 0.330 & 0.630 & 0.481 & 0.676 & 0.318 \\
\hline 1831 & 27 & 63.7 & 0.778 & 0.775 & 0.812 & 0.731 & 0.605 & 0.514 & 0.659 & 0.364 & 0.605 & 0.509 & 0.659 & 0.352 \\
\hline
\end{tabular}




\begin{tabular}{|c|c|c|c|c|c|c|c|c|c|c|c|c|c|c|}
\hline 1839 & 29 & 64.2 & 0.743 & 0.815 & 0.830 & 0.730 & 0.552 & 0.528 & 0.689 & 0.386 & 0.552 & 0.523 & 0.689 & 0.375 \\
\hline 1847 & 31 & 64.2 & 0.717 & 0.781 & 0.828 & 0.731 & 0.515 & 0.487 & 0.686 & 0.400 & 0.515 & 0.482 & 0.686 & 0.389 \\
\hline \multirow[t]{5}{*}{$1852^{\mathrm{b}}$} & 32 & 66.2 & 0.717 & 0.781 & 0.844 & 0.722 & 0.515 & 0.487 & 0.712 & 0.405 & 0.515 & 0.485 & 0.712 & 0.395 \\
\hline & & & \multicolumn{12}{|c|}{-- Forward Nests -- } \\
\hline & & & \multicolumn{4}{|c|}{ Pearson $r$} & \multicolumn{4}{|c|}{$\mathbf{R E}$} & \multicolumn{4}{|c|}{ CE } \\
\hline & & & Calib. & Veri. & Calib. & Veri. & Calib. & Veri. & Calib. & Veri. & Calib. & Veri. & Calib. & Veri. \\
\hline & & & \multicolumn{2}{|c|}{ First $3^{\text {rd }}$} & \multicolumn{2}{|c|}{ Second $3^{\text {rd }}$} & \multicolumn{2}{|c|}{ First $3^{\text {rd }}$} & \multicolumn{2}{|c|}{ Second $3^{\text {rd }}$} & \multicolumn{2}{|c|}{ First $3^{\text {rd }}$} & \multicolumn{2}{|c|}{ Second $3^{\text {rd }}$} \\
\hline $1995^{\mathrm{c}}$ & 31 & 57.8 & 0.712 & 0.693 & 0.779 & 0.719 & 0.506 & 0.400 & 0.606 & 0.443 & 0.506 & 0.396 & 0.606 & 0.436 \\
\hline $1999^{\mathrm{d}}$ & 30 & 51.3 & 0.700 & 0.675 & 0.736 & 0.644 & 0.490 & 0.379 & 0.541 & 0.135 & 0.490 & 0.364 & 0.541 & 0.098 \\
\hline $2000^{\mathrm{e}}$ & 28 & 54.2 & 0.733 & 0.670 & 0.739 & 0.652 & 0.537 & 0.388 & 0.546 & 0.090 & 0.537 & 0.374 & 0.546 & 0.054 \\
\hline $2001^{\mathrm{f}}$ & 20 & 49.3 & 0.673 & 0.694 & 0.744 & 0.647 & 0.453 & 0.375 & 0.554 & 0.184 & 0.453 & 0.359 & 0.554 & 0.144 \\
\hline $2002^{\mathrm{g}}$ & 4 & 33.8 & 0.673 & 0.485 & 0.629 & 0.588 & 0.405 & 0.207 & 0.396 & 0.235 & 0.405 & 0.185 & 0.396 & 0.194 \\
\hline
\end{tabular}




\begin{tabular}{|l|l|l|l|l|l|l|l|l|l|l|l|l|l|l|}
\hline $2003^{\mathrm{h}}$ & 2 & 31.5 & 0.612 & 0.561 & 0.560 & 0.612 & 0.375 & 0.293 & 0.314 & 0.332 & 0.375 & 0.276 & 0.314 & 0.300 \\
\hline
\end{tabular}

${ }^{\mathrm{a}}$ Date $=1^{\text {st }} \mathrm{yr}$ of nest; ${ }^{\mathrm{b}} 1837=$ common period of all 33 CRNS; ${ }^{\mathrm{c}}$ calibration period $=1895-1995$, calibration-verification periods $=1895-1928,1929-1995 ; \mathrm{d}$ calibration period $=1895-1999$, calibration-verification periods $=1895-1930,1931-$

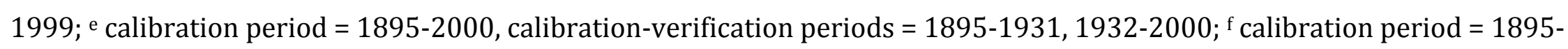
2001, calibration-verification periods $=1895-1932,1933-2001 ; \mathrm{g}$ calibration period $=1895-2002$, calibration-verification periods $=1895-1933,1934-2002 ;{ }^{\mathrm{h}}$ calibration period $=1895-2003$, calibration-verification periods $=1895-1934,1935-2003$. 
Table S3 - Top-10 drought events in the NYC Watershed since 1531.

\begin{tabular}{lcccc}
\hline Beginning Year & Duration & Magnitude & Intensity & Score \\
\hline $1962-1967$ & 6 & -18.87 & -3.14 & 69 \\
$1661-1667$ & 7 & -16.30 & -2.33 & 66 \\
$1630-1636$ & 7 & -15.09 & -2.16 & 63 \\
$1767-1773$ & 7 & -13.40 & -1.91 & 60 \\
$1748-1750$ & 3 & -7.76 & -2.59 & 58 \\
$1555-1577$ & 23 & -32.48 & -1.41 & 58 \\
$1697-1700$ & 4 & -8.51 & -2.13 & 56 \\
$1685-1692$ & 8 & -11.92 & -1.49 & 56 \\
$1647-1651$ & 5 & -9.17 & -1.83 & 56 \\
$1543-1545$ & 3 & -6.56 & -2.19 & 53 \\
\hline
\end{tabular}


Table S4 - Top-10 pluvial events in the NYC Watershed since 1531.

\begin{tabular}{lcccc}
\hline Beginning Year & Duration & Magnitude & Intensity & Score \\
\hline $1827-1834$ & 8 & 23.26 & 2.91 & 69 \\
$2006-2009 *$ & 4 & 15.21 & 3.80 & 67 \\
$1672-1680$ & 9 & 17.41 & 1.93 & 65 \\
$1971-1976$ & 6 & 14.15 & 2.36 & 64 \\
$1578-1584$ & 8 & 15.27 & 1.91 & 63 \\
$1751-1756$ & 6 & 12.22 & 2.04 & 59 \\
$1807-1815$ & 9 & 13.60 & 1.51 & 50 \\
$1538-1542$ & 5 & 8.52 & 1.70 & 49 \\
$1889-1892$ & 4 & 7.32 & 1.82 & 49 \\
$1901-1907$ & 7 & 10.7 & 1.53 & 48 \\
\hline$*=$ contains instrumental & & & &
\end{tabular}

$*=$ contains instrumental data 


\section{Supplemental Figures}

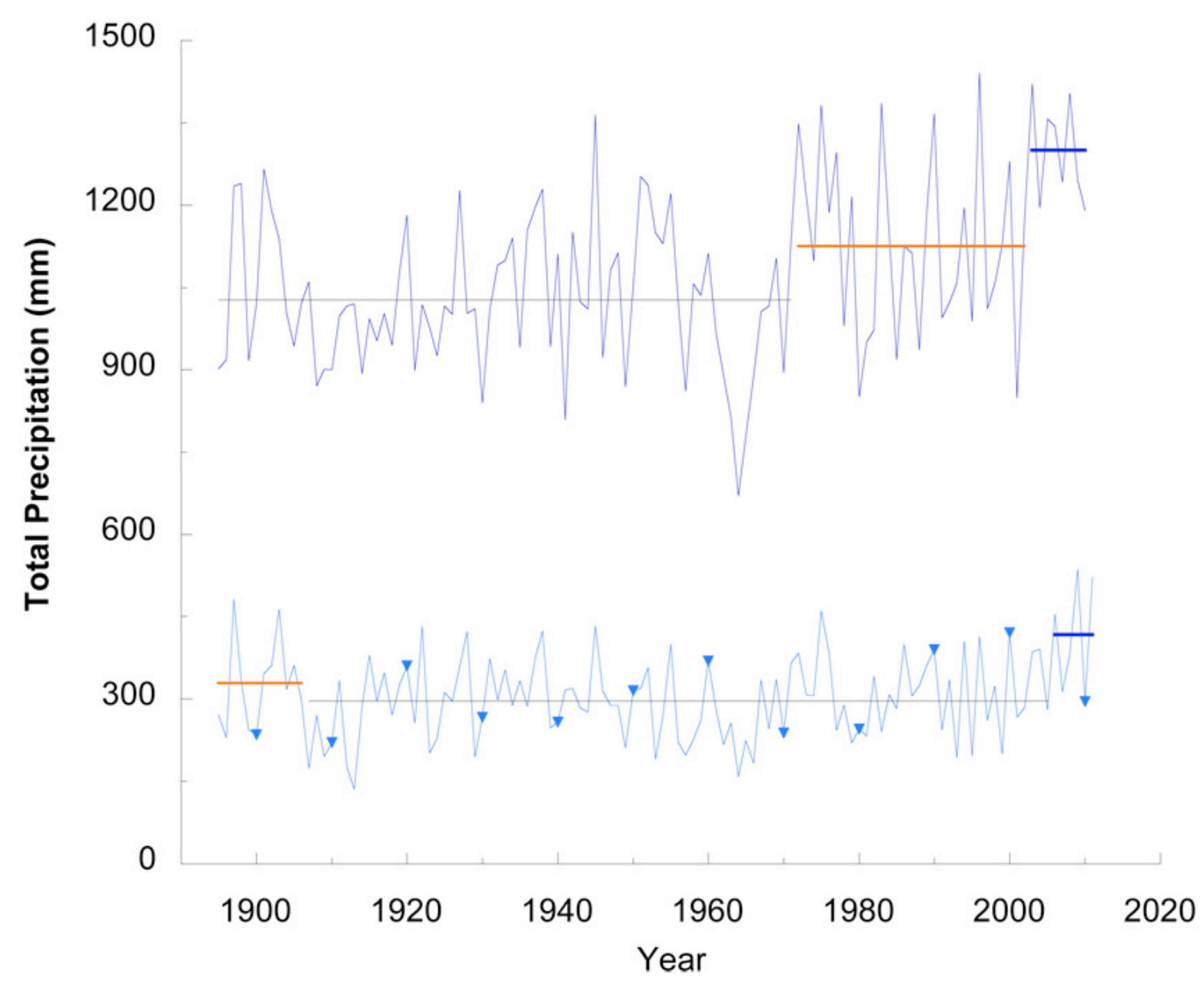

Fig S1 - Instrumental records of precipitation from 1895-2011 for the Hudson Valley of New York State. The top series (solid blue line) is average total annual precipitation while the bottom series (solid light blue line with triangles) is average total summer precipitation. Horizontal lines represent average precipitation for the regimes detected using the methods of Rodionov (2004). Data are derived from NOAA's National Climatic Data center for Climate Services and Monitoring Division (http://www.ncdc.noaa.gov/temp-and-precip/time-series/). 

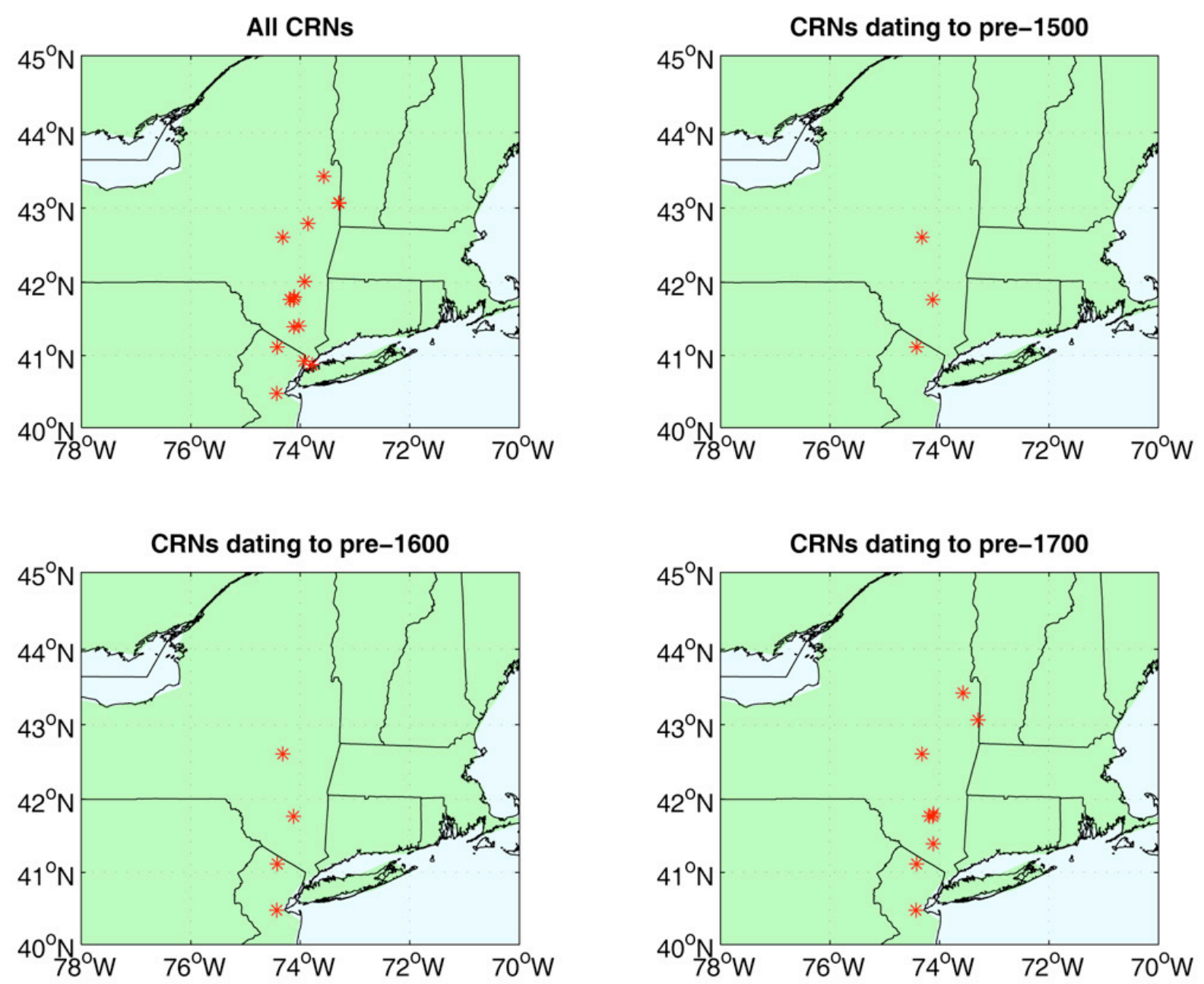

Fig S2 - Chronology network through time in the NYC Watershed. 


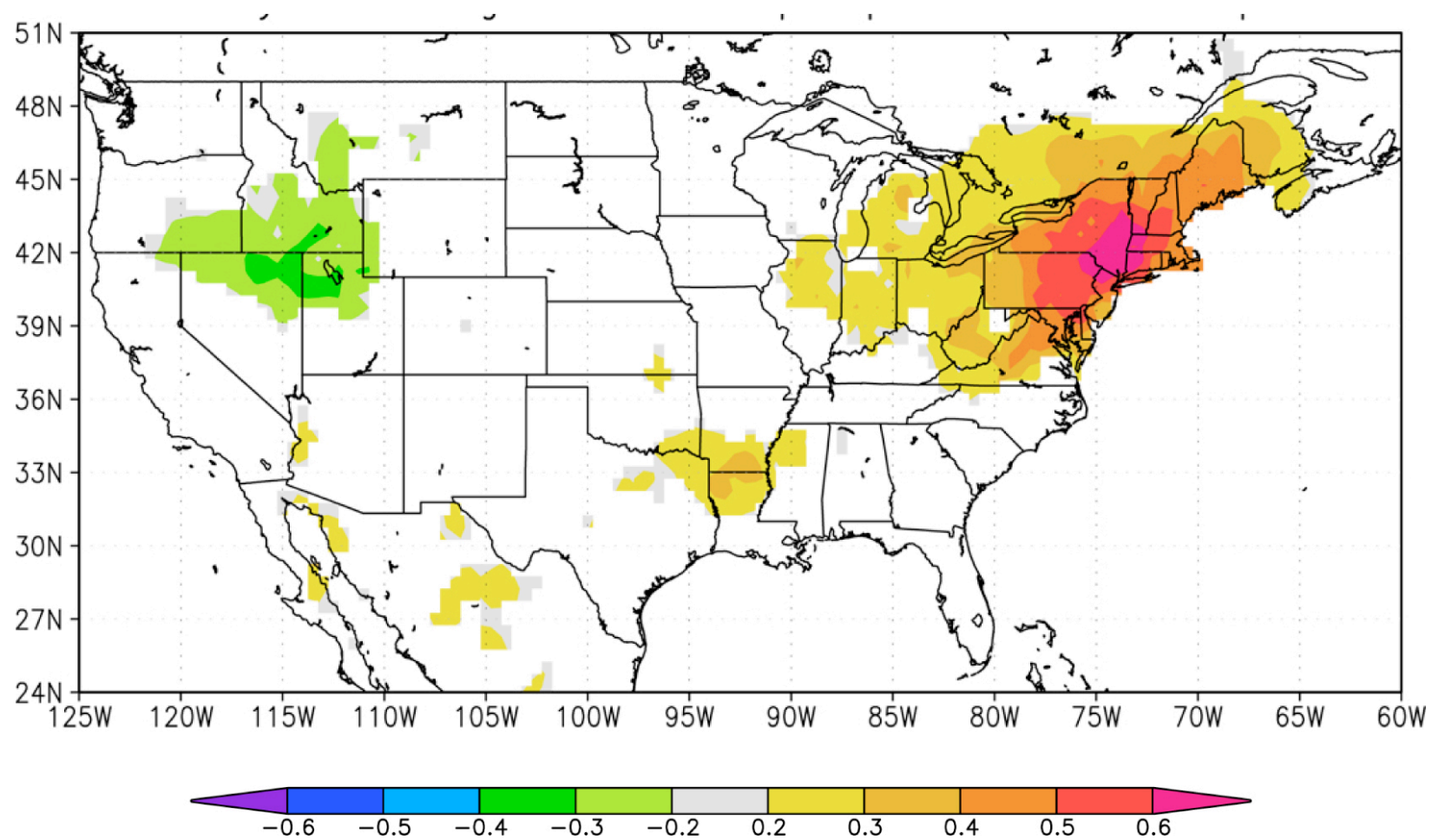

Fig S3 - Spatial correlation of reconstructed May-Aug PDSI versus May-Jul precipitation. Correlation conducted using KNMI Climate explorer (http://climexp.knmi.nl/) against CRU 3.1 precipitation from 1901-2006. 


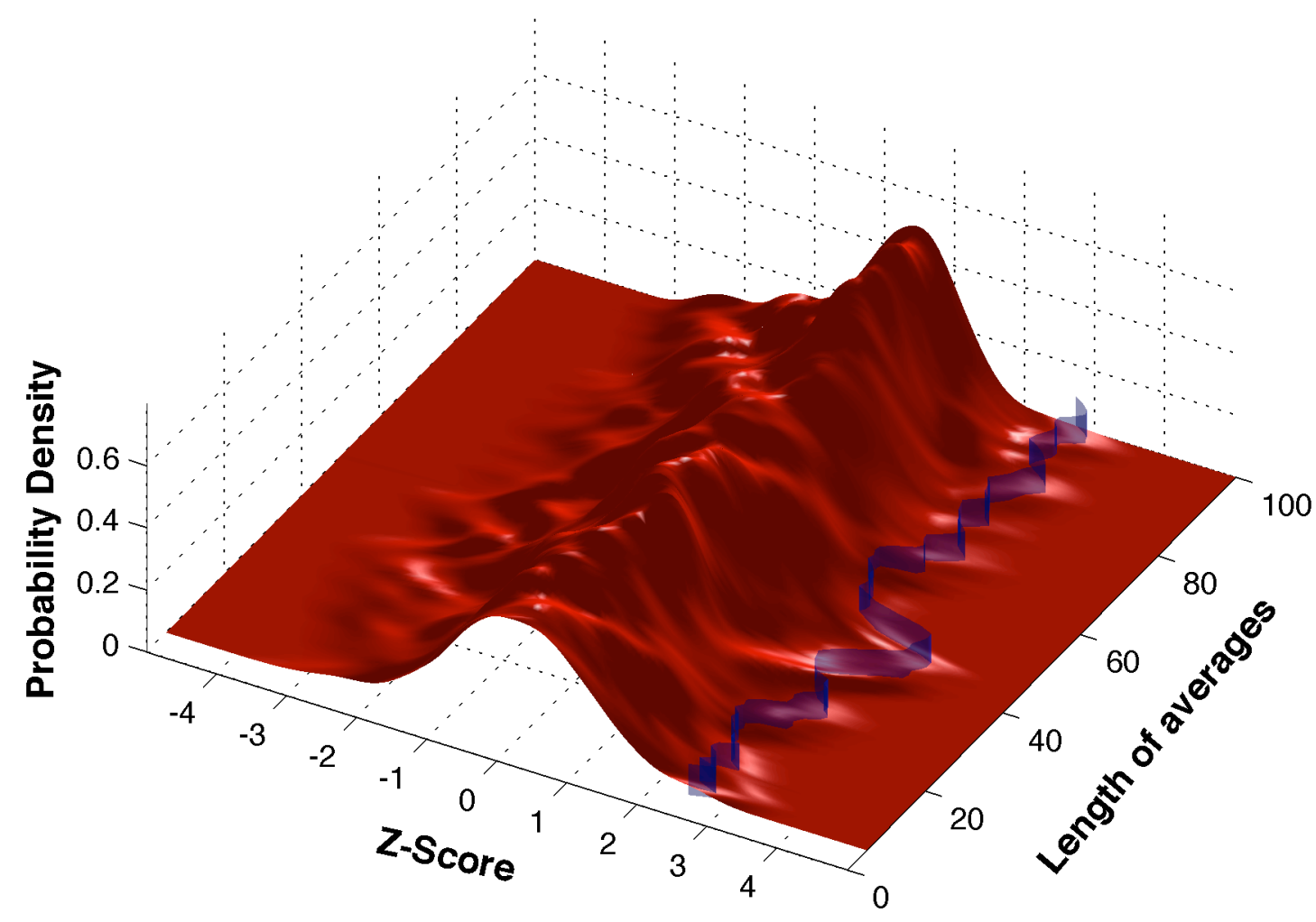

Fig S4 - Distribution of multi-year averages of NYC PDSI (expressed as Z-scores) from 15312011. Data are expressed as Z-scores. Blue ribbon represents the most recent period (i.e., the most recent $X$-year average up to 2011). The most recent period is increasingly anomalous in the broader climate context (i.e., a trend of increasing Z-score) moving back from 5-year to about 45-year averages, where the average incorporates the 1960s drought. 


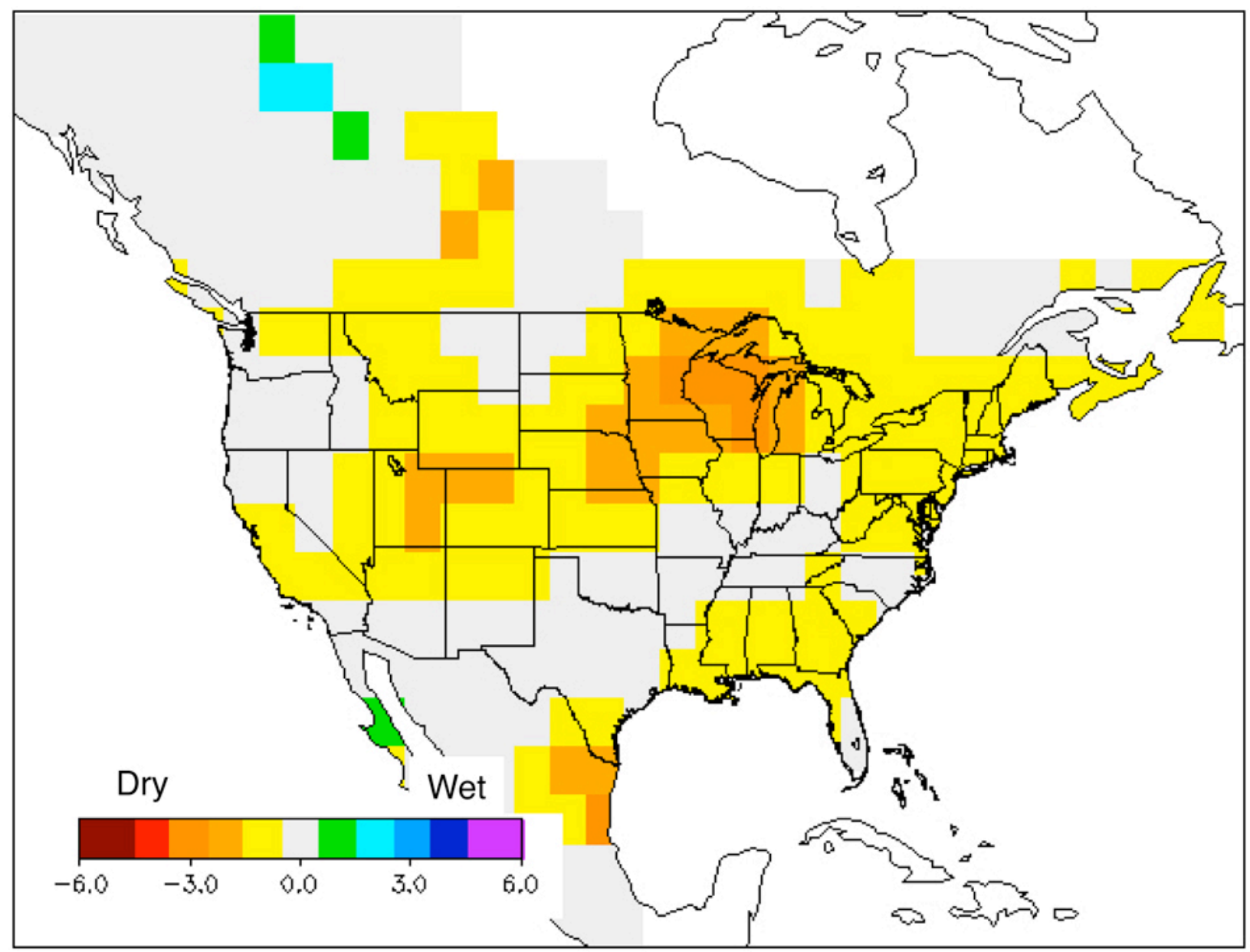

Fig S5 - Spatial pattern of drought across North America from 1661-1667. Adapted from the North American Drought Atlas (Cook et al. 1999; Cook and Krusic 2004; Cook and al. 2008; http://www.ncdc.noaa.gov/cgi-bin/paleo/pd08plot.pl). 

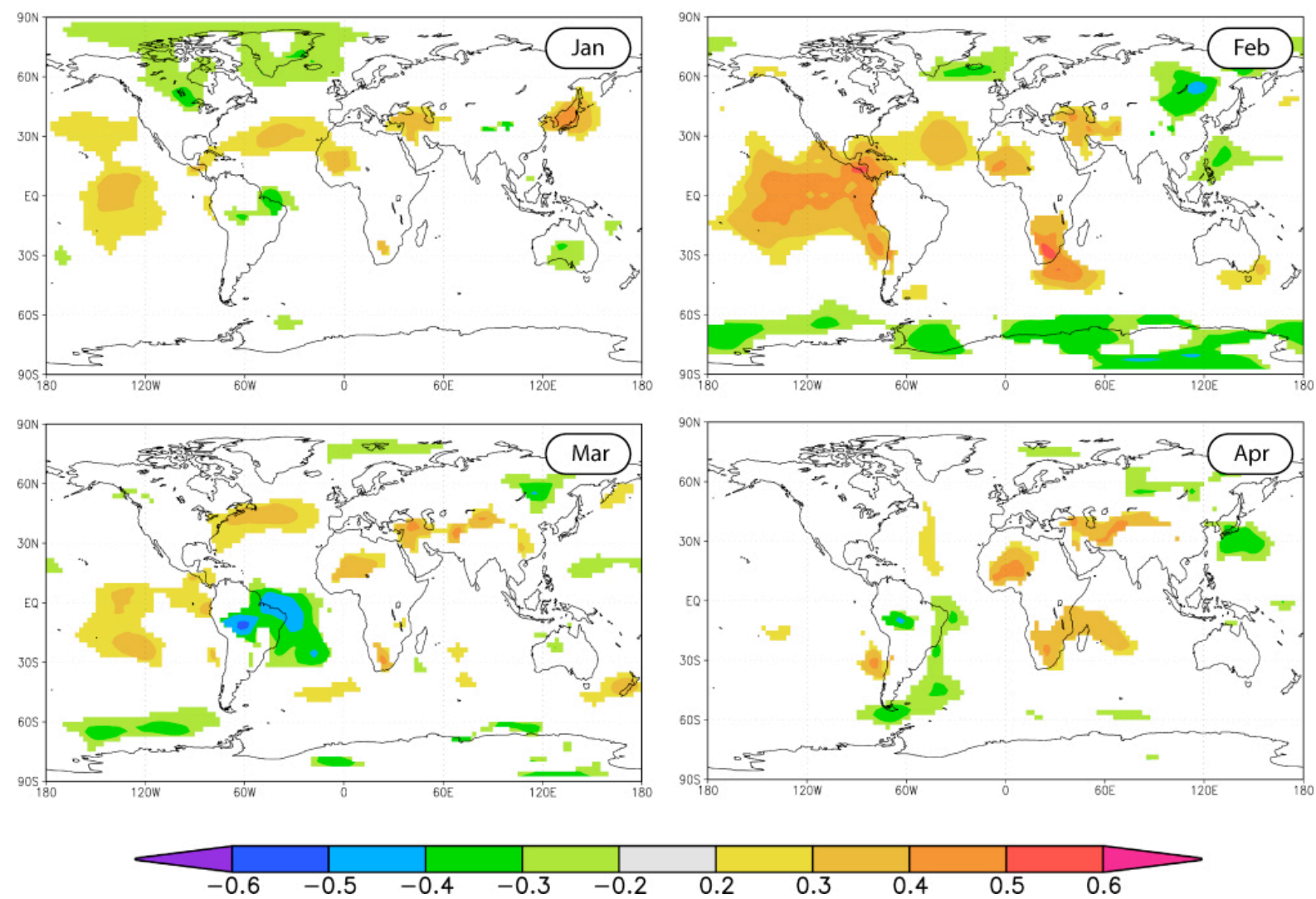

Fig S6 - Correlation between the NYC watershed drought reconstruction and average January, February, March and April sea-level pressure data from 1948-2009 (Kalnay et al. 1996). Adapted from the KNMI Climate explorer (http://climexp.knmi.nl/). 


\section{Supplemental Text}

\section{Implications for Tree-ring Based Reconstructions in Mesic Regions}

We found that Liriodendron tulipifera was found to be one of the best species to reconstruct hydroclimate, a finding similar in the reconstruction of the Potomac River (Maxwell et al. 2011). Liriodendron tulipifera has two traits that make it nearly an ideal replacement of Tsuga canadensis. First, its AREV value is nearly equal to Tsuga canadensis (Table 1). However, the next trait that makes Liriodendron tulipifera an especially appealing replacement species is that it has recently been documented as often living longer than 400 years (Eastern OLDLIST 2011). In fact, the new documented maximum age for Liriodendron tulipifera of 512 years is from a hollow tree where only half of its radius was recovered (Pederson 2010). It would not be surprising if Liriodendron tulipifera's maximum age reaches 600 years, if not 700 years, with future sampling. The only limitation for this species is that it does not live as far north or in the cold environments like Tsuga canadensis. Until disease or a pest is found to significantly impact Liriodendron tulipifera, this species seems like the best replacement for Tsuga canadensis.

Three other species new to dendroclimatic research are recommended as potential replacements for Tsuga canadensis or, at the very least, useful for dendrohydroclimatic research: Betula lenta, Carya glabra and Quercus rubra. Each has good AREV values and can be regularly found more than 200 years in age. It is not too unusual to find Betula lenta and Carya glabra 250-300+ years old (Pederson et al. 2005, Eastern OLDLIST 2011). Continued exploration of species like Carya glabra will likely reveal greater ages as has been found for other less-well studied species like Betula lenta. While Quercus rubra's AREV is relatively low, one chronology has a value $=4.00$, which is greater than the median AREV of all 
chronologies used here (2.59). One limitation is that Quercus rubra rarely reaches more than 300 years (Orwig et al. 2001, Eastern OLDLIST 2011).

\section{Literature Cited}

Cook, E. R., and P. J. Krusic, 2004: The North American Drought Atlas. Lamont-Doherty Earth Observatory and the National Science Foundation,. http://iridl.ldeo.columbia.edu/SOURCES/.LDEO/.TRL/.NADA2004/.pdsi-atlas.html (Accessed November 8, 2011).

Cook, E. R., and et al., 2008: North American Summer PDSI Reconstructions, Version 2a. IGBP PAGES/World Data Center for Paleoclimatology Data Contribution Series \# 2008046. NOAA/NGDC Paleoclimatology Program,. http://www.ncdc.noaa.gov/paleo/pdsi.html (Accessed November 11, 2011).

Cook, E. R., D. M. Meko, D. W. Stahle, and M. K. Cleaveland, 1999: Drought reconstructions for the continental United States. Journal of Climate, 12, 1145-1162.

Eastern OLDLIST, Eastern OLDLIST: a database of maximum tree ages for eastern North America. 2011, http://www.ldeo.columbia.edu/ adk/oldlisteast/ (Accessed December 1, 2011).

Kalnay, E. and Coauthors, 1996: The NCEP/NCAR 40-year reanalysis project. Bulletin of the American Meteorological Society, 77, 437-471.

Maxwell, R. S., A. E. Hessl, E. R. Cook, and N. Pederson, 2011: A multispecies tree ring reconstruction of Potomac River streamflow (950-2001). Water Resources Research, 47, 1-12, doi:10.1029/2010WR010019.

Orwig, D. a, C. V. Cogbill, D. R. Foster, and J. F. O'Keefe, 2001: Variations in old-growth structure and definitions: forest dynamics on Wachusett Mountain, Massachusetts. Ecological Applications, 11, 437-452.

Pederson, N., 2010: External Characteristics of Old Trees in the Eastern Deciduous Forest. Natural Areas Journal, 30, 396-407.

Pederson, N., A. W. D’Amato, and D. A. Orwig, 2005: Natural History from Dendrochronology: Maximum Ages and Canopy Persistence of Rarely Studied Hardwood Species. Proceedings of the 15th Central Hardwood Forest Conference, Eds. D.S. Buckley and W.K. Clatterbuck, Asheville, U.S. Department of Agriculture Forest Service Southern Research Station, 695-701. 
Rodionov, S. N., 2004: A sequential algorithm for testing climate regime shifts. Geophysical Research Letters, 31, 2-5. 